Chapman University

Chapman University Digital Commons

ESI Working Papers

Economic Science Institute

$10-2019$

\title{
Investment Choice Architecture in Trust Games: When "All-in" Is Not Enough
}

Joaquin Gómez-Miñambres

Chapman University, gomezmij@lafayette.edu

Eric Schniter

Chapman University, schniter@chapman.edu

Timothy W. Shields

Chapman University, shields@chapman.edu

Follow this and additional works at: https://digitalcommons.chapman.edu/esi_working_papers

Part of the Econometrics Commons, Economic Theory Commons, and the Other Economics Commons

\section{Recommended Citation}

Gómez-Miñambres, J., Schniter, E., \& Shields, T. W. (2019). Investment choice architecture in trust games: When "all-in" is not enough. ESI Working Paper 19-24. Retrieved from https://digitalcommons.chapman.edu/esi_working_papers/284/

This Article is brought to you for free and open access by the Economic Science Institute at Chapman University Digital Commons. It has been accepted for inclusion in ESI Working Papers by an authorized administrator of Chapman University Digital Commons. For more information, please contact laughtin@chapman.edu. 


\section{Investment Choice Architecture in Trust Games: When "All-in" Is Not Enough}

Comments

ESI Working Paper 19-24

A peer-reviewed version of this paper was later published in:

Gómez-Miñambres, J., Schniter, E. \& Shields, T.W. (2021). Investment choice architecture in trust games: When "all-in" is not enough. Economic Inquiry, 59(1), 300-314. https://doi.org/10.1111/ ecin. 12939 


\title{
Investment Choice Architecture in Trust Games: When "All-in" Is Not Enough
}

\author{
Joaquín Gómez-Miñambres a, b \\ Eric Schniter ${ }^{b, c}$ \\ Timothy W. Shields ${ }^{b, c}$ \\ ${ }^{a}$ Department of Economics, Lafayette College \\ 730 Hight Street, Easton, PA 18042, USA \\ ${ }^{\mathrm{b}}$ Economic Science Institute, Chapman University \\ One University Drive, Orange, CA 92866, USA \\ ${ }^{c}$ Argyros School of Business and Economics, Chapman University \\ One University Drive, Orange, CA 92866, USA
}

\begin{abstract}
While many economic interactions feature "All-or-Nothing" options nudging investors towards going "all-in", such designs may unintentionally affect reciprocity. We manipulate the investor's action space in two versions of the "trust game". In one version investors can invest either "all" their endowment or "nothing". In the other version, they can invest any amount of the endowment. Consistent with our intentions-based model, we show that "all-or-nothing" designs coax more investment but limit investors' demonstrability of intended trust. As a result, "all-in" investors are less generously reciprocated than when they can invest any amount, where full investments are a clearer signal of trustworthiness.
\end{abstract}

JEL Classifications: C72, C90, C91, D63, D64, L51 


\section{Introduction}

Human exchange likely evolved among ancient hominids as a survival strategy under conditions characterized by resource holding asymmetries and asynchronous opportunities to control resource distribution. ${ }^{1}$ These conditions required that successful exchange relationships rely on trust and trustworthiness (Cosmides and Tooby 1992; Isaac 1978). Relationships in modern economies continue to share in the gains and efficient transactions possible from trustbased asynchronous exchange: by relying on trust, the otherwise necessary costs of contracting and monitoring can be reduced or eliminated (e.g., Fukuyama 1995).

Interactions that require trust involve a basic dilemma where security (e.g. by not investing) is traded off with the benefits of developing a trust-based reciprocity relationship with the trustee. Trust based reciprocity relationships are based on trust, trustworthiness, and mutual benefit: trustors who are trusting decide to forgo security in expectation of trustworthy trustees that will avoid opportunism and provide mutual benefit (e.g., McCabe et al. 2003). Berg et al. (1995) formalized this dilemma using a simple sequential game where investments are efficiency enhancing but investors are unable to enforce returns from trustees.

In this paper we study the effects that different investor choice sets have on investments, returns, and trust attributions in the trust game. In particular, two questions motivate our study. First, can we generate more investment by restricting the investor's choice set to an "All-orNothing" (either investing their entire endowment or keeping it) option? Second, if we can generate higher investment using All-or-Nothing restrictions, will higher investment lead to

\footnotetext{
${ }^{1}$ The frequency and breadth of trust humans show in strangers is curious, because we do not see analogues of this among our closely related primates (Seabright 2010).
} 
higher reciprocity or might it "backfire" on investors (e.g. resulting in lower or even negative returns)? Results addressing these questions are of interest to managers, social and financial planners, and behavioral economists for a couple of reasons. First, investors' options are often restricted (we review some examples below), making it important to know whether such restrictions are economically efficient. The increasingly popular practice of intentionally manipulating people's “choice architecture" (Münscher, Vetter, and Scheuerle 2016) has led to documented economic improvements for both investors and trustees, making it of great interest to social and financial planners (Thaler and Sunstein 2009). Second, many behavioral economists use and refer to results of "trust games" with highly restricted action spaces (e.g., only two or three options), considering these equivalent to "trust games" with more continuous action spaces. An improved understanding of how trust game environments affect trust and reciprocity should be of great importance to many, given the explosion in literature making the "trust game" a very popular topic of study (for reviews see Balliet, D.P. et al. 2013; Johnson and Mislin 2011).

\subsection{Background}

Trust-based investment involves uncertainty: trustees are cautious about attributing trust to investors, not all show interest in developing trust-based reciprocity relationships, and many dismiss smaller investments as insufficient demonstrations of trust -- consequently returning less than originally invested (Ostrom and Walker 2003). Our first research goal is to study the effects of restricting the action space that governs the amount that can be invested in the trust game. In trust-based interactions in and outside of the lab, both endogenous and exogenous alterations to investors' choice architecture have been explored. While we review both types below, our paper concerns exogenously imposed choice restrictions. 
Endogenously imposed investment choice restrictions. Weber et al. (2004) report several examples of investors signaling their trust by voluntarily taking on handicaps. In one of these examples, they reference a documented phenomenon where potential parties in a merger eliminate alternative suppliers to signal their commitment to the exchange relationship and make it easier for the other party to also commit. Similarly, "deep" relationships (e.g. as found between close friends, mates, business partners) are often cultivated when people become vulnerable and interdependent: such as when sensitive personal information is disclosed that provides the partner opportunity to later exploit this information if the relationship deteriorates. By disincentivizing their own extra-pair opportunities in the future and thereby reducing their partner's risk of abandonment in times of need, "deeply engaged" partners can demonstrate their relationship commitment and protect their partners from feeling "replaceable" (Tooby and Cosmides 1996).

Restrictions are sometimes imposed on a first mover's choice space by the trustee. For example, in the risky world of entrepreneurial investment, a minimum investment (e.g. of $\$ 25,000)$ is typically required from an angel investor for opportunity to invest in a startup company (Sudek 2006). Minimum “pledges” are also common requirements to support projects on www.kickstarter.com, the world's largest funding platform. Experimental studies using appeals scales (a form of choice architecture manipulation), demonstrate that fundraisers can increase net donations by suggesting discrete contribution levels slightly higher than previous modal contributions (Desmet and Feinberg 2003).

Exogenously imposed investment choice restrictions. Many game interactions studied feature investor action spaces that have been limited by the experimenter's design. It has been unclear how restrictive choice designs might reliably raise or lower net transfers in laboratory 
games. In the context of a threshold public goods game, for example, Cadsby and Maynes (1999) find lower levels of contribution when participants are provided binary rather than continuous action spaces. On the other hand, in the context of linear public goods games Gangadharan and Nikiforakis (2009) do not find differences in levels of contribution using binary (i.e., 0 or 10) versus integer (i.e., $0,1, \ldots 10$ ) action spaces. In the context of binary trust games, Bolle (1998) and Eckel and Wilson (2004) provide investors All-or-Nothing investment options and find an especially high investment rate: 76 and 80 percent of investors, respectively, send the full amount. Eckel and Wilson's (2004) game both (i) restricts the investor and trustee action space, and (ii) frames the amount sent by the investor as a "loan." Bolle's (1998) game (i) uses a different multiplier than Berg et al. (1995), (ii) pairs two investors with each trustee, and (iii) uses a lottery to pay only 4 of the 64 pairs. Thus, the reason for increased investment is unclear. Given these conflicting findings, it remains to be seen how restricting investment options would impact investments in a trust game where trustees have freedom to return any proportion of the multiplied investment.

Whether more restricted investment options affect reciprocity is a second important question motivating this research. A few studies suggest that the relationship between investment rate and reciprocity may not be so straightforward: if investment does not provide much information about whether the investor values a trust-based reciprocity relationship, trustees may not reciprocate (e.g., Bacharach et al. 2007; Dufwenberg and Kirchsteiger 2004; Falk and Fischbacher 2006; Rabin 1993). We suggest that the investor's action space affects the demonstrability of trust in its ability to reveal that the investor has forgone available alternatives to secure some portion of their endowment and avoid the downside risk otherwise associated with investment. Investment demonstrated in an environment of more (fewer) alternatives 
provides the trustee a clearer (more ambiguous) indication of how much an investor values a trust-based reciprocity relationship.

To better understand how restriction of investor action space affects investments and returns, we examine behavior in two versions of the trust game that we call the Continuous and All-or-Nothing trust games. In a second experiment, described below, we examine beliefs about trust attributions and expected behaviors in these games. In both the Continuous and All-orNothing trust games, the investor receives a $\$ 10$ endowment and then makes an investment decision. In both games, the un-endowed trustee receives the tripled amount of the investment and then can return any amount to the investor. The difference is that while Continuous investors can invest any amount of the \$10 endowment; All-or-Nothing investors can only invest either \$0 or \$10. In both Continuous and All-or-Nothing games the trustee choice set (i.e., to return any amount) is equally unrestricted. ${ }^{2}$

We provide testable hypotheses using a simple model where individuals differ on how willing they would be to engage in a trust-based reciprocity relationship. We formalize this by assuming that some investors and trustees suffer from "guilt" when not fully trusting their partners. We show that trustee's reciprocation of an investment increases with the amount invested and with her belief about the investor's true intentions. Our model thus combines

\footnotetext{
${ }^{2}$ Similar to Bolle (1998), Dufwenberg and Gneezy (2000), Glaeser et al., (2000), Xiao and Bicchieri (2010), and Rietz et al. (2018), the trustee is not endowed with $\$ 10$ as in Berg et al. (1995). This design makes salient the primordial social dilemma (with resource holding asymmetries and asynchronous opportunities) motivating our work, by initially giving the investor complete control over wealth distribution, and subsequently giving the vested trustee control. Additionally, this experimental design mirrors the luck-based endowment inequity that naturally precedes trust-based relationships across human societies (Kaplan et al. 2012), making zero investment a more salient anti-trust relationship behavior. As such, the second mover's state of relative poverty characterizes the adaptive problem under which human exchange psychology (capable of recognizing benefit opportunities from asynchronous exchange) evolved.
} 
elements of outcome-based and intention-based reciprocation. We provide an analytical proof that, under certain conditions, total investments would be larger in the All-or-Nothing game. However, a given investment is a clearer signal of intentions in the Continuous case, where it will be more generously reciprocated by trustees.

Our first of two experiments largely corroborates these theoretical conjectures. We find that investments are higher in the All-or-Nothing game than in the Continuous game (\$7.71 versus \$5.60). However, when investment is limited to a two-choice option, as in the All-orNothing game, reciprocity decreases. On average trustees who receive $\$ 30$ income (from $\$ 10$ investment) return less in the All-or-Nothing game than in the Continuous game ( $\$ 10.03$ versus \$13.00). These results suggest that investor action space restriction affects trustee reciprocation: while trustees use investment amounts to index investor trust and reciprocate based on this, the all-or-nothing action space restricts demonstrations of trust and trustees' ability to index investor trust.

In a second incentivized experiment with a second group of participants, we manipulate the versions of the "trust game" described (All-or-Nothing, Continuous) to investigate effects on beliefs about investor trust and expectations about trustee reciprocity. Results indicate that while investors going all-in are viewed as more trusting and expected to receive larger returns, the allin investors in the all-or-nothing game were viewed as less trusting and likely to receive smaller returns than the all-in investors in the continuous game. Despite these effects, participants still expected positive returns on all-in investments made in the all-or-nothing game. On average, returns on all-in investments were zero in the all-or-nothing game of the first experiment. These results suggest that while All-or-Nothing designs are expected to result in more investment and tend to have this effect, their effect on lower reciprocity, while not entirely unexpected, may be 
underappreciated. Generally, our results support the proposition that perceptions of intended trust are formed not only by evaluating what others do but also by evaluating what others choose not to do.

\section{Theoretical Framework}

Our model set-up is based on the trust (or investment) game introduced by Berg et al. (1995) representing a basic two-person interaction in which players may choose cooperative moves sequentially to achieve a mutually beneficial outcome. The first mover or "investor" is initially endowed with $M$ dollars. The investor decides on an "investment" amount $x \in[0, M]$ to be sent to the second mover or "trustee". Any amount sent is multiplied $r>1$ times so that the trustee receives an income of $r x$ dollars. The trustee then can return $y \leq r x$ dollars to the investor, keeping any remaining income for herself. The investor cannot prevent the trustee from keeping the income for herself. The investor may, however, trust that the trustee will reciprocate the original investment and some of the profit it generated. We summarize the structure of the experiment in Figure 1, which also includes participants' payoffs in all the decision nodes.

\section{--- Figure 1 Here: Monetary Payoffs in the Trust Game ---}

The standard game theoretic prediction of the trust game (sequential Nash equilibrium) is straightforward. There is no investment $(x=0)$ and no reciprocity $(y=0)$ among players if the preference for immediate and autonomous money-maximization is widely shared and common knowledge. This solution is framed in the rectangle below "Don't invest" in Figure 1. A more efficient outcome arises if the investor deviates from this solution and sends a positive amount to the trustee $(x>0)$. We denote this as the "Invest" outcome. Finally, note that both participants receive a higher payoff in the Invest outcome if $x<y<r x$. Starting with Berg et al. (1995), 
numerous experiments have reported evidence in favor of the Invest outcome and, in many cases, both players end up increasing their initial endowments (see Camerer 2003 for a survey of the trust game literature and Johnson and Mislin 2011 for a meta-analysis).

From a theoretical standpoint, a model where people derive utility from having successfully interacted with another in a trust-based reciprocity relationship helps explain the trust and trustworthy reciprocity easily observed between strangers. Existing social preference models of altruism (Levine 1998) or inequity aversion (Fehr and Schmidt 1999), for example, have been applied to explain the emergence of cooperative solutions in the trust game. The common feature of these models is that they attempt to explain the results by focusing on the properties of the outcomes of the game. In other words, they focus on the observed actions rather than the intentions behind those actions. The empirical evidence, however, has emphasized that players in the trust game try to read each other's intentions (a process commonly known as "mentalizing" or "mind reading" which depends on a "theory of mind") rather than focusing exclusively on the observed actions. For example, in games where the investor is exogenously "forced" to invest, the trustee's level of reciprocation is significantly lower than when the investor freely chooses investment (McCabe, Rigdon, and Smith 2003). Likewise, investment levels can be depressed when trustees are forced to provide some return (Rietz et al. 2018).

\subsection{The Role of Intentions in Trust-Based Reciprocity Relations}

We depart from the standard model described above by considering a situation where individuals differ in their willingness to engage in a trust-based reciprocity relationship. To formalize this, we assume that individuals might experience negative emotions like guilt and insecurity (Gómez-Miñambres and Schniter 2017a, 2017b). In particular, we assume that an 
investor might suffer guilt $-\beta(M-x)^{2}$ - when not fully trusting a trustee. Similarly, a trustee might suffer guilt $-\beta(r x-y)^{2}$ - when not fully reciprocating the transfer received from the investor. We also assume that investors might experience insecurity $-\alpha x^{2}$ - when trusting a trustee, which can be understood as the investors' aversion to appear gullible. We consider a model with two types of people (low and high) indexed by $i \in\{L, H\}$ that differ in their willingness to engage in trust-base relations. For simplicity we assume that the low (high) type suffers only from insecurity (guilt) when trusting (not trusting). However, none of the results described below will be different in a more general model where types suffer from a mix of guilt and insecurity, provided that the high type's guilt (insecurity) is higher (lower) than the low type's guilt (insecurity). We also assume that the high type values trust-based reciprocity relationships with other high types more than with low types. We interpret this as people caring about the "true intentions" of the other person in the relationship. If we denote by $\beta_{j}>0$ to be the high type's guilt for not trusting type $j$, this means that $\beta_{H}>\beta_{L}$. We assume that people know there is a proportion $p \in(0,1)$ of type $H$ individuals in the population and we denote by $\theta=P[H \mid x]$ the trustee's belief that investor is of type $H$ given investment $x$. Given this belief, a high type trustee's guilt is given by $\hat{\beta}(\theta)=\theta \beta_{H}+(1-\theta) \beta_{L}$.

Here forward we refer to a high (low) type investors as "trusting" ("non-trusting"), and to a high (low) type trustee as "trustworthy" ("non-trustworthy"), as this nomenclature fits our model set-up. While a non-trusting investor will never invest any money unless he expects the return to compensate his insecurity, a trusting investor will extend trust to avoid the guilt associated with a low investment. Similarly, a trustworthy trustee will return money to the investor (again, to minimize guilt) while a non-trustworthy trustee will keep all the money 
received from the investor. In this sense, the parameter $\beta_{j}$ can be understood as a person's degree of trust or trustworthiness when interacting with a type $j$ person.

The utility functions of non-trusting and trusting investors are respectively:

$$
\begin{gathered}
U_{L}(x ; \theta)=M+E_{\theta}\left[y \mid x_{i}\right]-x_{i}-\frac{1}{2} \alpha x_{i}^{2} \\
U_{H}(x ; \theta)=M+E_{\theta}\left[y \mid x_{i}\right]-x_{i}-\frac{1}{2} \hat{\beta}(p)\left(M-x_{i}\right)^{2}
\end{gathered}
$$

As in the standard trust game model, the investor's utility is given by his initial endowment $(M)$ plus the expected return from investment given trustee's beliefs $\left(E_{\theta}\left[y \mid x_{i}\right]-x_{i}\right)$. The last components of the utility function capture emotional consequences faced by participants in a trust-based relationship. On the one hand, a trusting investor suffers from the aforementioned "guilt" when not fully trusting (i.e., investing the endowment). We assume that guilt decreases with the amount invested $\left(\frac{1}{2} \hat{\beta}(p)\left(M-x_{i}\right)^{2}\right) \cdot{ }^{3}$ On the other hand, the low type investors suffer from insecurity when trusting (i.e., investing more than 0 ). We assume that insecurity increases with the amount invested $\left(\frac{1}{2} \alpha x_{i}^{2}\right)$.

The utility of a trustworthy trustee is given by:

$$
V_{H}(y ; \theta)=r x-y_{i}-\frac{1}{2} \hat{\beta}(\theta)\left(r x-y_{i}\right)^{2}
$$

\footnotetext{
${ }^{3}$ Note that, as a first mover in the Trust game, the investor's belief that the trustee is trustworthy is given by the prior $p$, therefore the high type investor's guilt is given by $\hat{\beta}_{i}(p)=p \beta_{i H}+(1-p) \beta_{i L}$.
} 
Thus, her feeling of "guilt" decreases with the amount returned. Note that an untrustworthy trustee does not suffer neither guilt nor insecurity because, as the second mover, she decides what the final allocation will be with certainty.

$$
V_{L}(y ; \theta)=r x-y_{i}
$$

Given an investment, a trustee chooses a level of reciprocation such that:

$$
y_{i}(\theta)=\underset{y}{\operatorname{argmax}} V_{i}=\left\{\begin{array}{cc}
r x-\frac{1}{\hat{\beta}(\theta)} & \text { if } i=H \\
0 & \text { if } i=L
\end{array}\right.
$$

Note that, while a non-trustworthy trustee does not reciprocate anything, a trustworthy trustee's reciprocation increases with the investment received and with her guilt given belief $\theta$. This illustrates how our model combines "outcome-based" and "intention-based" elements of reciprocity.

The expected return from investment is given by:

$$
E_{\theta}[y \mid x]-x=p y_{H}(\theta)+(1-p) y_{L}(\theta)-x=x(p r-1)-\frac{p}{\hat{\beta}(\theta)}
$$

Given this expected return, the optimal (unconstrained) investment of investor $i$ is given by:

$$
x_{i}^{*}=\underset{x}{\operatorname{argmax}} U_{i}=\left\{\begin{array}{c}
M+\frac{2}{\hat{\beta}(\theta)}(p r-1) \quad \text { if } i=H \\
\frac{p r-1}{\alpha} \quad \text { if } i=L
\end{array}\right.
$$


Note that $x_{i}^{*}>0$ for all $i$ provided that $p>\frac{1}{r}$. Given the multiplier $(\times 3)$ in our laboratory experiment, this condition is satisfied whenever the proportion of trusting participants is greater than $1 / 3$. Moreover, since the investment cannot be higher than the endowment, the optimal investments in this case are given by:

$$
x_{H}^{*}=M \text { and } x_{L}^{*}=\max \left\{\frac{p r-1}{\alpha}, M\right\}
$$

In order to connect the theory with our experimental design, we now examine results of the model across two possible variants of the trust game. In the All-or-Nothing game $(A N)$ the investor can invest either $\$ M$ or $\$ 0$; thus $x^{A N} \in\{0, M\}$. In the Continuous game $(C)$ the investor can invest any amount between $\$ M$ and $\$ 0$; thus $x^{C} \in[0, M]$.

Proposition 1. Let $p$ be greater than $\frac{1}{r}$, then in equilibrium, $x_{L}^{C}<x_{L}^{A N}=M$, if the following conditions are satisfied:

$$
\begin{aligned}
& \text { (i) } U_{L}\left(x_{L}^{*} ; 0\right)>U_{L}(M ; 1) \Leftrightarrow \frac{1}{\beta_{L}}-\frac{1}{\beta_{H}}<\frac{(\alpha M-(p r-1))^{2}}{2 \alpha p} \\
& \text { (ii) } U_{L}(M ; p)>U_{L}(0 ; 0)=M \Leftrightarrow p \beta_{H}+(1-p) \beta_{L}>\frac{p}{M\left((p r-1)-\frac{1}{2} \alpha M\right)} \\
& \text { (iii) } \frac{M}{2}<x_{L}^{*}<M \Leftrightarrow \frac{p r-1}{M}<\alpha<2(p r-1)
\end{aligned}
$$

\section{Proof: See Appendix A.}

Proposition 1 provides the conditions for an equilibrium in which the trusting and not trusting investors invest the same in $A N$ but differently in $C$. This is the most interesting 
equilibrium of the game and it is the one that helps us understand our experiment results. ${ }^{4}$

Condition (i) ensures that the not trusting investor will not want to mimic the trusting investor's full investment strategy in $C$. This condition holds when $\beta_{L}$ and $\beta_{H}$ are not too far apart, so the expected return of investing $x_{L}^{*}<M$ is not much lower than the expected return of investing $M$. Condition (ii) ensures that investing $M$ is an equilibrium in $A N$. This condition holds when guilt $\beta_{i}$ is high enough. Finally, (iii) simply provides necessary conditions for (i) and (ii). In Figure 2 below, we plot the non-trusting investor's utility under the conditions of Proposition 1.

\section{--- Figure 2 Here: Non-trusting investor's utility if $x_{L}^{C}<x_{L}^{A N}=M$---}

If the conditions of Proposition 1 hold, then average investments will be higher in $A N$ than in $C$ :

$$
E\left[x^{C}\right]=p M+(1-p) x_{L}^{*}<M=E\left[x^{A N}\right]
$$

In this case, investments are a clear signal of intentions (i.e., being the trusting type) in $C$, because different types of investors choose different investment levels (i.e., a separating equilibrium). However, in $A N$, when all investors invest the full amount (i.e., a pooling equilibrium), trustees are unable to infer the investor's type. In other words, when observing an investment of $M$, the trustee's beliefs that the investor is trusting are $\theta=1$ in $C$, but only $\theta=$ $p<1$ in $A N$. Because trustees care about trusting intentions, this implies that full investments will be reciprocated more generously in $C$ than in $A N$ (see Figure 3). However, the comparison

\footnotetext{
${ }^{4}$ The other possible equilibria are: (i) $x_{L}^{C}=x_{L}^{A N}=M$ and (ii) $x_{L}^{C}=0<x_{L}^{A N}<M$. None of them seem to arise in our experiment.
} 
of average reciprocation between games is not straightforward from Proposition 1. The following corollary summarizes these comparisons.

Corollary 1. From the investment solutions of $C$ and $A N$ it follows that:

(i) $\quad y_{i}^{C}\left|M>y_{i}^{A N}\right| M$ for all $i$

$$
E\left[y^{C}\right]=p E_{1}[y \mid M]+(1-p) E_{0}\left[y \mid x_{L}^{C}\right]<E_{p}[y \mid M]=E\left[y^{A N}\right]
$$

\section{Proof: See Appendix A.}

Therefore, investments and reciprocations are on average higher in $A N$, however and investment of $M$ will be more generously reciprocated in $C$. This is because, in our model, trustees' willingness to reciprocate is in part determined by his assessment of the investor's type, and while $M$ is only a noisy signal in $A N$, in $C$ investing $M$ is a clear signal of being trusting.

In Figure 3, we plot the expected return for different investments given the equilibrium

beliefs when $x_{L}^{C}<x_{L}^{A N}=M$. Note that the separating equilibrium in $C$ makes the increase to full investment steeper than in $A N$ with a pooling equilibrium. This is because, given the equilibrium in $C$, the trustee believes that the investor is non-trusting when observing any $x<M$ (i.e., $\theta=0$ ) but she believes that the investor is trusting when observing $x=M$ (i.e., $\theta=1$ ). In our intentions-based trust model, learning that the investor is trusting generates an increase in the trustee's willingness to reciprocate. Similarly, an investment of $x=M$ will be less generously reciprocated in $A N$ because in a pooling equilibrium the trustee is not sure about the investor's type (i.e., $\theta=p$ ).

--- Figure 3 Here: Expected return on investments if $x_{L}^{C}<x_{L}^{A N}=M$--- 


\section{Predictions}

Our theory combines outcome-based and intention-based elements of reciprocity. In particular, both the trustee's reciprocation and the expected return minus investment $\left(E_{\theta}[y \mid x]-\right.$ $x$ ) should increase with the amount invested. As such, higher investments provide a clearer signal that the investor is trusting. In fact, in the continuous case, a high investment fully reveals that the investor is trusting so the reciprocation rate should accelerate. This leads us to our first prediction.

Prediction 1: The relationship between investments and returns is increasing and convex.

Our model also generates our second prediction about an investment difference expected between the Continuous and All-or-Nothing treatments.

Prediction 2: Average investment in the All-or-Nothing treatment is higher than in the Continuous treatment.

We also expect to see differences in trustees' behavior despite their action space being identical between treatments. Our model (Corollary 1.ii) generates our third prediction about average return differences between treatments.

Prediction 3: Average return in the All-or-Nothing treatment is greater than in the Continuous treatment.

In our experiment, outcome-based models do not predict different returns across treatments on the same investments; however, according to our model, where demonstrable trust matters, we expect trustees to show these differences. This is because the investor's action space 
affects the trustee's evaluation of trust for a given investment. Investors who invest $\$ 10$ in the Continuous treatment demonstrate that they are sufficiently trusting, because they could have invested less (say $\$ 7$ or $\$ 8$ ) but chose to go "all-in" $(\$ 10)$. While the demonstration of sufficient trust with high investment is likely to be reciprocated with a high return (Fehr, Gächter, and Kirchsteiger 1996; Gächter and Falk 2002; Ostrom and Walker 2003), investors who invest all $\$ 10$ in the All-or-Nothing treatment cannot clearly demonstrate that they have sufficient trust in the trustee, because their only alternative is to invest nothing. ${ }^{5}$ As such, the amount invested in the All-or-Nothing treatment is a less convincing demonstration of trust. Our model (Corollary 1.i) generates our fourth prediction about differences across treatment in returns on "all-in" $\$ 10$ investments.

Prediction 4: Conditional on investment of \$10, the return in the All-or-Nothing treatment is lower than in the Continuous treatment.

\section{Design and Procedures}

\subsection{Experiment 1}

We conducted Experiment 1 at Chapman University's Economic Science Institute (ESI). A total of 268 participants were recruited from a participant pool consisting primarily of undergraduate students and randomly assigned to a single session. Across sessions, we manipulated the investor's action space by using two versions of the Trust game (Continuous,

\footnotetext{
${ }^{5}$ Falk et al. (2003) find that in ultimatum games the rejection rate by the second mover of a proposed distribution (80/20) differs depending upon the alternative(s) the first mover had (i.e., a single 20/80 alternative versus both 20/80 and 50/50 alternatives). The authors claim that the intention behind the proposal is assessed in light of the options foregone, as the second mover was more likely to reject the 80/20 split when the proposer could have offered an equal division. Nelson (2002) and Charness and Rabin (2002) report similar results.
} 
All-or-Nothing), as described above and in the instructions (see Appendix B). There were eight sessions of the Continuous treatment $(\mathrm{N}=172)$ and four of the All-or-Nothing treatment $(\mathrm{N}=$ 96). Those who had participated in trust-based experiments at ESI were excluded. Participants were seated at visually isolated workstations and interacted with each other anonymously over a local computer network. The experiment was programmed and conducted using z-Tree (Fischbacher 2007).

Each of twelve sessions consisted of 18 to 24 participants, lasted approximately 35 minutes, and was sequenced as follows. First, an experimenter read the instructions aloud while each participant followed along with their own copy of the instructions. The instructions explained the experimental procedures and payoffs used in the experiment (see Appendix B). After finishing the instructions, participants were given five minutes to write down their answers to several questions to ensure that they understood the instructions (see Appendix B). Participants' answers remained confidential. After participants completed the quiz, the experimenter distributed a printed copy of the correct quiz answers. The experimenter privately answered any questions regarding the experimental procedures.

The computer randomly assigned participants into pairs and each participant within a pair was randomly assigned a role, labeled "person 1" for the investor and "person 2" for the trustee. Each pair played the Continuous or All-or-Nothing version of the trust game one time. Each participant was paid $\$ 7$ for participation and an average of $\$ 11.36$ from payoffs of the trust game.

\subsection{Experiment 2}


We conducted Experiment 2 at Chapman University's Economic Science Institute (ESI) after the first experiment described above. A total of 189 participants were recruited from a participant pool consisting primarily of undergraduate students and randomly assigned to a single session. Across sessions, we manipulated the version of the game (Continuous, All-or-Nothing) described in a set of incentivized belief elicitation tasks (see Appendix B). There were five sessions with the Continuous version $(\mathrm{N}=94)$ and five sessions with the All-or-Nothing version $(\mathrm{N}=95)$. Those who had participated in trust-based experiments at ESI, including Experiment 1 described above, were excluded from recruitment. Participants were seated at visually isolated workstations and interacted with each other anonymously over a local computer network.

Each of ten sessions consisted of 23 to 24 participants and lasted approximately 30 minutes. First, participants read the instructions on screen. The instructions explained the concluded Experiment 1 and its payoffs, as well as possible payoffs in Experiment 2 (see Appendix B). After finishing the instructions, the experimenter privately answered any questions regarding the experimental procedures. Next participants answered four sets of questions (see Appendix B). The order of the sets was randomly determined to be set 1 through 4 , or set 4 to set

1. Each participant was paid $\$ 7$ for participation and an average of $\$ 8.65$ from payoffs of Experiment 2.

\section{Results}

\subsection{Experiment 1}

We found no significant differences between sessions of a given treatment, so we report the combined results for both treatments of Experiment 1 in 
Table 1. Figure 1 displays a bubble plot of the amount sent and returned in both treatments. There is substantial variability in individual behavior. On average, investors in the Continuous treatment invest $\$ 5.60$ and trustees return $\$ 5.78$, resulting in average earnings of $\$ 10.18$ for the investors and $\$ 11.03$ for the trustees. Return on investment (ROI) is $-.15 .^{6}$ These results are consistent with previous findings of Berg et al. (1995), despite the aforementioned differences in the games (i.e., in investment options and trustee endowment). In the All-orNothing treatment, on average investors invest $\$ 7.71$ and trustees return $\$ 7.73$, resulting in average earnings of $\$ 10.02$ for the investors and $\$ 15.40$ for the trustees. ROI is .00 . The results of Experiment 1 that we report below are consistent with our theoretical predictions, namely that returns increase with the amount invested at an increasing rate (Result 1) and that while there is overall more investment (Result 2) and greater return (Result 3) in the All-or-Nothing than in the Continuous treatment, reciprocity for an "all-in" investment actually decreases in the All-orNothing treatment (Result 4).

Because investments, earnings and ROI in the two treatments have different variances, we use the two-sample robust rank-order test for analyzing differences between treatments (Feltovich 2003).

Result 1: In the Continuous treatment return from investment (return minus investment) increases in the amount invested at an increasing rate

Figure 4 illustrates that in the Continuous treatment larger investments tend to result in larger ROI. For example, investments less than $\$ 7$ generate average returns smaller than the

\footnotetext{
${ }^{6} \mathrm{ROI}$ is defined as (return - investment)/investment, and is not defined when investment is zero, thus the reduction in observations.
} 
investment, yielding negative $\mathrm{ROI}(\mathrm{M}=-.473, \mathrm{Mdn}=-.633, \mathrm{SEM}=.078, \mathrm{~N}=42)$. However, investments $\$ 7$ or greater on average generate positive $\mathrm{ROI}(\mathrm{M}=.278, \mathrm{Mdn}=.456, \mathrm{SEM}=.068$, $\mathrm{N}=32$ ). A simple OLS regression, where the independent variable is the investment and the dependent variable is ROI, confirms that the relationship between ROI and investment is significant $\left(\beta=.65, \mathrm{t}(72)=7.30, \mathrm{p}<.01, \mathrm{~N}=74, \mathrm{~F}(172)=53.28\right.$, Adj. $\left.\mathrm{R}^{2}=.417\right)$. A quadratic OLS regression, where the dependent variable is the return and the independent variable is investment, results in better fit $\left(\mathrm{N}=86, \mathrm{~F}(2,83)=134.36\right.$, Adj. $\mathrm{R}^{2}=0.758$, Bayesian information criterion $(\mathrm{BIC})=437.93)$ than a linear model of investment $\left(\mathrm{F}(1,84)=215.00\right.$, Adj. $\mathrm{R}^{2}=.716$, $\mathrm{BIC}=448.47)$. The increase in Adj. $\mathrm{R}^{2}$ is significant $(\mathrm{F}(1,83)=15.81, \mathrm{p}<.001)$. This quadratic regression is plotted in Figure 2.

Result 2: Investment in the All-or-Nothing treatment (\$7.71) is higher than in the Continuous treatment $(\$ 5.60)$.

Consistent with Prediction 2, investment is higher in the All-or-Nothing treatment than in the Continuous treatment based on the robust rank-order test $(\mathrm{U}=3.222, \mathrm{p}<.001)$. In the Continuous treatment fewer investors (59\%) invest $\$ 5$ or more, compared to the All-or-Nothing treatment (77\%), a significant difference according to Fischer's exact test $\left(\mathrm{p}=.028, \mathrm{~N}_{1}=48, \mathrm{~N}_{2}\right.$ $=86$ ). Finally, there is little difference in the proportion of $\$ 0$ investments between the All-orNothing treatment and the Continuous treatment (23\% versus 14\%). Fisher's exact test indicates the difference is not significant $\left(\mathrm{p}=0.223, \mathrm{~N}_{1}=48, \mathrm{~N}_{2}=86\right)$.

Despite the increase in investment, investor's earnings in the All-or-Nothing treatment and the Continuous treatment do not differ $(\mathrm{U}=.831, \mathrm{p}=.203)$. The increase in wealth created by increased investment is captured by trustees who earn more $(\mathrm{U}=3.293, \mathrm{p}<.001)$ in the All- 
or-Nothing treatment than trustees in the Continuous treatment. The pattern is robust when examining only results where investment was greater than zero: investor's earnings in the All-orNothing treatment and the Continuous treatment do not differ $(\mathrm{U}=0.854, \mathrm{p}=.197)$, and trustees earn more $(\mathrm{U}=9.316, \mathrm{p}<.001)$ in the All-or-Nothing treatment than trustees in the Continuous treatment.

Result 3: Consistent with Prediction 3, return in the All-or-Nothing treatment is greater than in the Continuous treatment.

As reported in Table 1, conditional on some level of investment, average returns are significantly greater in the All-or-Nothing treatment than in the Continuous treatment $(\mathrm{U}=2.382$, $\mathrm{p}=.009$ ). The average return is a function of average investment, which is constrained but greater in the All-or-Nothing treatment. To examine differential reciprocity across treatments, we restrict our attention to comparable levels of investments.

Result 4: Consistent with Prediction 4, conditional on full investment of $\$ 10$, the average ROI in the All-or-Nothing treatment is significantly lower than in the Continuous treatment.

As reported in Table 1, conditional on full investment, average ROI is significantly greater in the All-or-Nothing treatment than in the Continuous treatment $(\mathrm{U}=1.978, \mathrm{p}=.024)$. As shown in Figure 3, in the All-or-Nothing treatment, $19 \%$ of trustees return $\$ 0,8 \%$ of trustees return less than $\$ 10,24 \%$ return exactly $\$ 10$, and $49 \%$ return more than $\$ 10$ (untabulated). In contrast, in the Continuous treatment only $4 \%$ of trustees return $\$ 0,21 \%$ return exactly $\$ 10$, and $75 \%$ return more than $\$ 10$ (untabulated). The proportion of $\$ 10$ investments earning a ROI greater than zero is lower in the All-or-Nothing treatment (73\%) than in the Continuous treatment 
$(96 \%)$ based on Fisher's exact test $\left(\mathrm{p}=.022, \mathrm{~N}_{1}=37, \mathrm{~N}_{2}=24\right)$, a result that is consistent with our theoretical conjectures (Prediction 4).

\subsection{Experiment 2}

No significant differences were found between sessions of a given treatment, as well as no significant differences from question order of a given treatment, so we report the combined results of all sessions and orders below.

The results of Experiment 2 are consistent with the premises of our theory. In particular, people believe that investors with different degrees of trust exist in a population and expect they will invest differently if allowed to, but -when restricted by All-or-Nothing options_-people expect investors will indistinguishably pool together with "all-in" investments. Our model proposes that people perceive this pooling of investor trust types under All-or-Nothing restrictions and respond accordingly. To provide further evidence that people expect and perceive what the model proposes, we examine results of our incentivized belief elicitation experiment.

First, we asked participants to reveal the investment that they expect a person with a certain degree of trust (not trusting, barely trusting, somewhat trusting, mostly trusting, completely trusting) would make in a version of the Trust game. Next, we asked participants to predict the investments that other participants in their session would expect invested, given the degree of trust attributed to an investor. The results of these predictions are displayed in Figure 6 (panel 
a). ${ }^{7}$ For the Continuous treatment, we see steadily increasing predicted investment over increasing degrees of attributed trust. In the All-or-Nothing treatment participants predicted that investment would increase across degrees of attributed trust, though the increase they predicted is less steady across the five degree of trust than what they predicted in the Continuous treatment. For four of the five degrees of trust we asked about, we find significantly different participant predictions between treatments using the two-sample robust rank-order test.

To illustrate how investors with different degrees of trust are expected to pool together, indistinguishably choosing identical all-in investment amounts in the All-or-Nothing treatment (but otherwise showing more investment variation in the Continuous treatment), we assemble and compare proportions of all-in investments (of \$10) expected by participants for each degree of trust attributed to an investor, and display these in Figure 6 panel (b). Data from the incentivized belief elicitation task suggests that a hypothetical trustee observing the all-in $\$ 10$ investment in the Continuous version would be almost assured (97\%) in believing that the investor was "completely trusting". However, in the All-or-Nothing version a hypothetical trustee observing the all-in $\$ 10$ investment would be less assured of the investor's degree of trust, believing that they could be anywhere from "somewhat trusting" ( $\approx 20 \%)$, to "mostly trusting" $(\approx 40 \%)$, or "completely trusting" $(\approx 40 \%)$. This result is important as it provides evidence for the underlying mechanism behind our theory. In particular, our key prediction that full investments will be more generously reciprocated in the Continuous treatment because they provide a clearer signal of the investor to be trusting.

\footnotetext{
${ }^{7}$ In Figure 6 we report the results of question 2, where participants are predicting what other participants reported in question 1. Since question 2 is incentive compatible, we elect to report these results. However, reporting and analyzing the results of question 1 , as opposed to question 2 , results in comparable results and conclusions.
} 
To see if participants expected different average investment across treatments, we examine the results of question 3, a belief elicitation task where participants predict what percentage of investors invested a given amount. Figure 7 displays predicted investment in experiment 2 (in bars) and actual results of experiment 1 (as a connected line). While the direction is consistent with our theory, we find no significant difference between the average invested in the All-orNothing treatment $(\mathrm{M}=5.34, \mathrm{SEM}=.26)$ and the Continuous treatment $(\mathrm{M}=4.99, \mathrm{SEM}=.19)$. The average investment in experiment 1 was greater than predicted (7.71 for the All-or-Nothing treatment and 5.60 for the Continuous treatment), and this difference is significant ( $<<.001$ for both treatments) ${ }^{8}$

Figure 8 suggests that investments are perceived as a relatively noisier proxy of investor trust in the All-Or-Nothing version. To see whether participants expect this perception to affect reciprocity, we examine results of the last question in the set of belief elicitation tasks, where we asked participants to predict how much trustees would return when receiving a maximum investment. While the amounts predicted are greater than the actual observed averages from Experiment 1, we find similar directional results. The average of $\$ 12.72$ (SEM $=.46)$ that participants expect returned in the All-or-Nothing treatment is significantly lower than the average of $\$ 14.44(\mathrm{SEM}=.59)$ expected in the Continuous treatment $(\mathrm{U}=2.340, \mathrm{p}=.009)$. In

\footnotetext{
${ }^{8}$ It is also clear from the graph that people underestimate the probability of observing $\$ 10$ investments in both Allor-Nothing and Continuous treatments. This means that people likely underestimate the proportion of completely trusting subjects in the population (i.e., the prior - $p$ - in our model). While this underestimation does not affect the direction of our theory results and hence predictions, it might affect the magnitude of the treatment differences. In particular, it would increase the difference in reciprocation of $\$ 10$ investments between All-or-Nothing and Continuous treatments. This is because, while in Continuous the trustee infers the investor's type regardless of the prior, in All-or-Nothing the posterior belief is equal to her (underestimated) prior so she would reciprocate less than if she has the right priors.
} 
both treatments, participants expect positive returns on all-in investments, though we only observe them in the Continuous treatment of Experiment 1.

\section{Discussion}

Our experiment was motivated by two questions: (i) can we generate more investment by restricting the investor's choice set to an All-or-Nothing option?, and (ii) if we can generate higher investment using All-or-Nothing restrictions, will higher investment lead to higher reciprocity or might it "backfire" for investors? In our first experiment we found that (i) indeed, we can coax more investment with an All-or-Nothing design than with a Continuous design, but (ii) that the All-or-Nothing design also results in paradoxically low reciprocity for investors who do not share in the increased wealth.

These results are consistent with our intentions-based theoretical framework showing that the forced choice between extreme All-or-Nothing options leads to both non-trusting and trusting investors indistinguishably going "all in". When these investor types pool together under All-orNothing conditions that obfuscate the demonstrability of trust, the intention behind an investors' all-in investment is ambiguous. In the All-or-Nothing treatment where non-trusting investors (to whom trustees are less willing to reciprocate) and trusting investors (to whom trustees are more willing to reciprocate) cannot be distinguished, trustees are more discouraged from reciprocating investments than in the Continuous treatment where investor trust intentions are distinguished more easily.

Results from our second experiment reveal that most participants expect others to show the greater tendency towards "all-in" investment behaviors that we report observing under Allor-Nothing conditions of our first experiment. Most participants believe and expect others to 
believe that an investor's level of investment in the Continuous condition positively correlates with the investor's level of trust. As such, participants believe that investment signals trust in the Continuous condition. But our second experiment also confirms that most participants believe and expect others to believe that non-trusting investors (along with trusting investors) are more likely to go "all-in" in the All-or-Nothing treatment. As such, participants believe that investments cannot function as discriminant signals in the All-or-Nothing treatment, consistent with our explanation for why they also expect lower rates of trustee reciprocation.

Most studies measuring trust employ variants of either a continuous version of the trust game of Berg et al. (1995) or, the binary version of the trust game of Güth et al. (1997), or other variants that limit participants to non-continuous choice options about transfer amounts. There are many early examples of often-cited studies (C. Camerer and Weigelt 1998; Dasgupta 1988; Kreps 1990), as well as later studies (Malhotra and Murnighan 2002; Schniter et al. 2013), referring to games with binary choices as "trust games". If reciprocity was purely motivated by distributional concerns (Bolton and Ockenfels 2000; Fehr and Schmidt 1999), we would expect equivalent reciprocity of same levels of investments regardless of the granularity of the investor's action space. While previous research furthers understanding of trust and reciprocity, the results of our first experiment demonstrating disparate behavior between different trust games suggest caution should be taken when comparing results from one game to the other. Results of our second experiment only strengthen this critical call for caution: participants beliefs and expectations indicate that these behavioral differences are expected and understood in terms of investors intentions to trust and trustees' intentions to reciprocate trust-based investment. Furthermore, while the fundamental determinants motivating trust and reciprocity in binary trust games should correspond to determinants of trust and reciprocity observed in continuous games, 
the degree to which these determinants actually motivate trust and reciprocity should depend on the granularity of the action space useful for signaling the calibration of internal motivations.

\section{References}

Bacharach, Michael, Gerardo Guerra, and Daniel John Zizzo. 2007. "The Self-Fulfilling Property of Trust: An Experimental Study." Theory and Decision 63 (4): 349-88. https://doi.org/10.1007/s11238-007-9043-5.

Balliet, D.P., van Lange, P. A. M., Social \& Organizational Psychology, and Amsterdam Global Change Institute. 2013. "Trust, Conflict and Cooperation: A Meta-Analysis." Psychological Bulletin 139 (5): 1090-1112. https://doi.org/10.1037/a0030939.

Berg, Joyce, John Dickhaut, and Kevin McCabe. 1995. "Trust, Reciprocity, and Social History." Games and Economic Behavior 10 (1): 122-142.

Bolle, Friedel. 1998. "Rewarding Trust: An Experimental Study." Theory and Decision 45 (1): 83-98. https://doi.org/10.1023/A:1004930101743.

Cadsby, Charles Bram, and Elizabeth Maynes. 1999. "Voluntary Provision of Threshold Public Goods with Continuous Contributions: Experimental Evidence." Journal of Public Economics 71 (1): 53-73. https://doi.org/10.1016/S0047-2727(98)00049-8.

Camerer, Colin F. 2003. Behavioral Game Theory: Experiments in Strategic Interaction. Behavioral Game Theory: Experiments in Strategic Interaction. New York, NY, US: Russell Sage Foundation.

Charness, Gary, and Matthew Rabin. 2002. "Understanding Social Preferences with Simple Tests." The Quarterly Journal of Economics 117 (3): 817-69. https://doi.org/10.1162/003355302760193904.

Cosmides, Leda, and John Tooby. 1992. "Cognitive Adaptations for Social Exchange." The Adapted Mind : Evolutionary Psychology and the Generation of Culture, 163-228.

Desmet, Pierre, and Fred M. Feinberg. 2003. "Ask and Ye Shall Receive: The Effect of the Appeals Scale on Consumers' Donation Behavior.” Journal of Economic Psychology 24 (3): 349-76. https://doi.org/10.1016/S0167-4870(02)00166-6.

Dufwenberg, Martin, and Uri Gneezy. 2000. "Measuring Beliefs in an Experimental Lost Wallet Game." Games and Economic Behavior 30 (2): 163-82. https://doi.org/10.1006/game.1999.0715.

Dufwenberg, Martin, and Georg Kirchsteiger. 2004. "A Theory of Sequential Reciprocity." Games and Economic Behavior 47 (2): 268-98. https://doi.org/10.1016/j.geb.2003.06.003. 
Eckel, Catherine C., and Rick K. Wilson. 2004. "Is Trust a Risky Decision?” Journal of Economic Behavior \& Organization, Trust and Trustworthiness, 55 (4): 447-65. https://doi.org/10.1016/j.jebo.2003.11.003.

Falk, Armin, Ernst Fehr, and Urs Fischbacher. 2003. "On the Nature of Fair Behavior." Economic Inquiry 41 (1): 20-26. https://doi.org/10.1093/ei/41.1.20.

Falk, Armin, and Urs Fischbacher. 2006. "A Theory of Reciprocity." Games and Economic Behavior 54 (2): 293-315. https://doi.org/10.1016/j.geb.2005.03.001.

Fehr, Ernst, Simon Gächter, and Georg Kirchsteiger. 1996. "Reciprocal Fairness and Noncompensating Wage Differentials." Journal of Institutional and Theoretical Economics (JITE) / Zeitschrift Für Die Gesamte Staatswissenschaft 152 (4): 608-40.

Fehr, Ernst, and Klaus M. Schmidt. 1999. "A Theory of Fairness, Competition, and Cooperation." The Quarterly Journal of Economics 114 (3): 817-68. https://doi.org/10.1162/003355399556151.

Feltovich, Nick. 2003. "Nonparametric Tests of Differences in Medians: Comparison of the Wilcoxon-Mann-Whitney and Robust Rank-Order Tests." Experimental Economics 6 (3): 273-97. https://doi.org/10.1023/A:1026273319211.

Fischbacher, Urs. 2007. “Z-Tree: Zurich Toolbox for Ready-Made Economic Experiments.” Experimental Economics 10 (2): 171-78. https://doi.org/10.1007/s10683-006-9159-4.

Fukuyama, Francis. 1995. Trust: The Social Virtues and the Creation of Prosperity. Glencoe, Illinois.: Free Press. https://repository.library.georgetown.edu/handle/10822/879473.

Gächter, Simon, and Armin Falk. 2002. "Reputation and Reciprocity: Consequences for the Labour Relation.” The Scandinavian Journal of Economics 104 (1): 1-26. https://doi.org/10.1111/1467-9442.00269.

Gangadharan, Lata, and Nikos Nikiforakis. 2009. "Does the Size of the Action Set Matter for Cooperation?" Economics Letters 104 (3): 115-17. https://doi.org/10.1016/j.econlet.2009.04.023.

Glaeser, Edward L., David I. Laibson, José A. Scheinkman, and Christine L. Soutter. 2000. "Measuring Trust." The Quarterly Journal of Economics 115 (3): 811-46. https://doi.org/10.1162/003355300554926.

Gómez-Miñambres, Joaquín, and Eric Schniter. 2017a. "Emotions and Behavior Regulation in Decision Dilemmas.” Games 8 (2): 22. https://doi.org/10.3390/g8020022.

- 2017b. "Emotional Calibration of Self-Control." Journal of Behavioral and Experimental Economics 68 (June): 110-18. https://doi.org/10.1016/j.socec.2017.04.003.

Isaac, Glynn. 1978. “The Food-Sharing Behavior of Protohuman Hominids.” Scientific American 238 (4): 90-109. 
Johnson, Noel D., and Alexandra A. Mislin. 2011. "Trust Games: A Meta-Analysis.” Journal of Economic Psychology 32 (5): 865-89. https://doi.org/10.1016/j.joep.2011.05.007.

Kaplan, Hillard S., Eric Schniter, Vernon L. Smith, and Bart J. Wilson. 2012. "Risk and the Evolution of Human Exchange." Proceedings of the Royal Society B: Biological Sciences 279 (1740): 2930-35. https://doi.org/10.1098/rspb.2011.2614.

Levine, David K. 1998. "Modeling Altruism and Spitefulness in Experiments." Review of Economic Dynamics 1 (3): 593-622. https://doi.org/10.1006/redy.1998.0023.

McCabe, Kevin A., Mary L. Rigdon, and Vernon L. Smith. 2003. "Positive Reciprocity and Intentions in Trust Games." Journal of Economic Behavior \& Organization 52 (2): 267 75. https://doi.org/10.1016/S0167-2681(03)00003-9.

Münscher, Robert, Max Vetter, and Thomas Scheuerle. 2016. "A Review and Taxonomy of Choice Architecture Techniques.” Journal of Behavioral Decision Making 29 (5): 51124. https://doi.org/10.1002/bdm.1897.

Nelson, William Robert. 2002. "Equity or Intention: It Is the Thought That Counts." Journal of Economic Behavior \& Organization 48 (4): 423-30. https://doi.org/10.1016/S01672681(01)00245-1.

Ostrom, Elinor, and James Walker. 2003. Trust and Reciprocity: Interdisciplinary Lessons for Experimental Research. Russell Sage Foundation.

Rabin, Matthew. 1993. "Incorporating Fairness into Game Theory and Economics." The American Economic Review 83 (5): 1281-1302.

Rietz, Thomas A., Eric Schniter, Roman M. Sheremeta, and Timothy W. Shields. 2018. "Trust, Reciprocity, and Rules.” Economic Inquiry 56 (3): 1526-42. https://doi.org/10.1111/ecin.12512.

Seabright, Paul. 2010. The Company of Strangers: A Natural History of Economic Life - Revised Edition. Princeton University Press.

Sudek, Richard. 2006. “Angel Investment Criteria.” Journal of Small Business Strategy 17 (2): $89-104$.

Thaler, Richard H., and Cass R. Sunstein. 2009. Nudge: Improving Decisions about Health, Wealth, and Happiness. Penguin.

Tooby, John, and Leda Cosmides. 1996. "Friendship and the Banker's Paradox: Other Pathways to the Evolution of Adaptations for Altruism." Evolution of Social Behaviour Patterns in Primates and Man, Proceedings of The British Academy, 88: 119-43.

Weber, J. Mark, Deepak Malhotra, and J. Keith Murnighan. 2004. "Normal Acts of Irrational Trust: Motivated Attributions and the Trust Development Process." Research in 
Organizational Behavior, An Annual Series of Analytical Essays and Critical Reviews, 26 (January): 75-101. https://doi.org/10.1016/S0191-3085(04)26003-8.

Xiao, Erte, and Cristina Bicchieri. 2010. "When Equality Trumps Reciprocity." Journal of Economic Psychology 31 (3): 456-70. https://doi.org/10.1016/j.joep.2010.02.001. 


\section{Figures and Tables}

Figure 1: Monetary Payoffs in the Trust Game

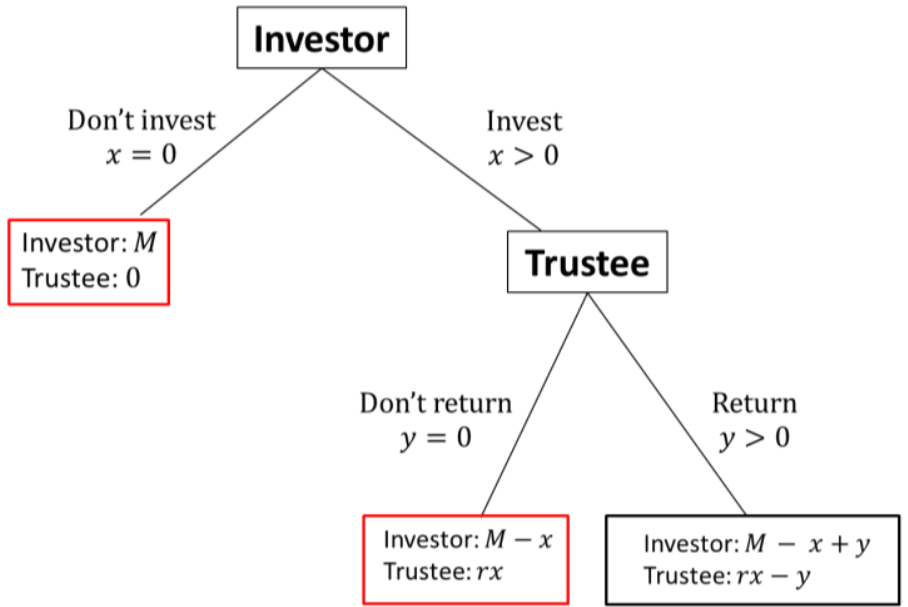

Note: The trust game is represented in extensive form. $M$ is the endowment, $x$ is the amount "invested" by the investor. Any amount sent is multiplied $r>1$ times so that the trustee receives an income of $r x$ dollars. The trustee can return $y \leq r x$ dollars to the investor. 
Figure 2: Non-trusting type's utility if $x_{L}^{C}<x_{L}^{A N}=M$

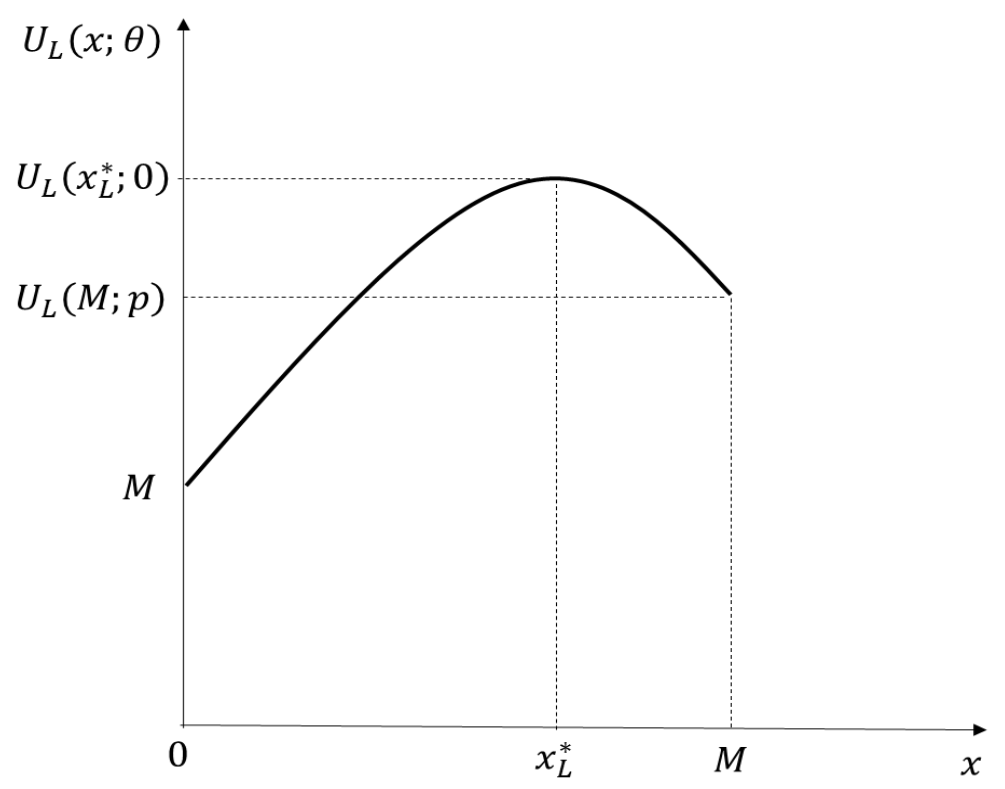

Note: The graph shows the utility of a non-trusting investor as a function of the investment. The inverted U-shaped form captures the trade-off between return from investment and the insecurity from trusting. 
Figure 3: Expected return on investments if $x_{L}^{C}<x_{L}^{A N}=M$

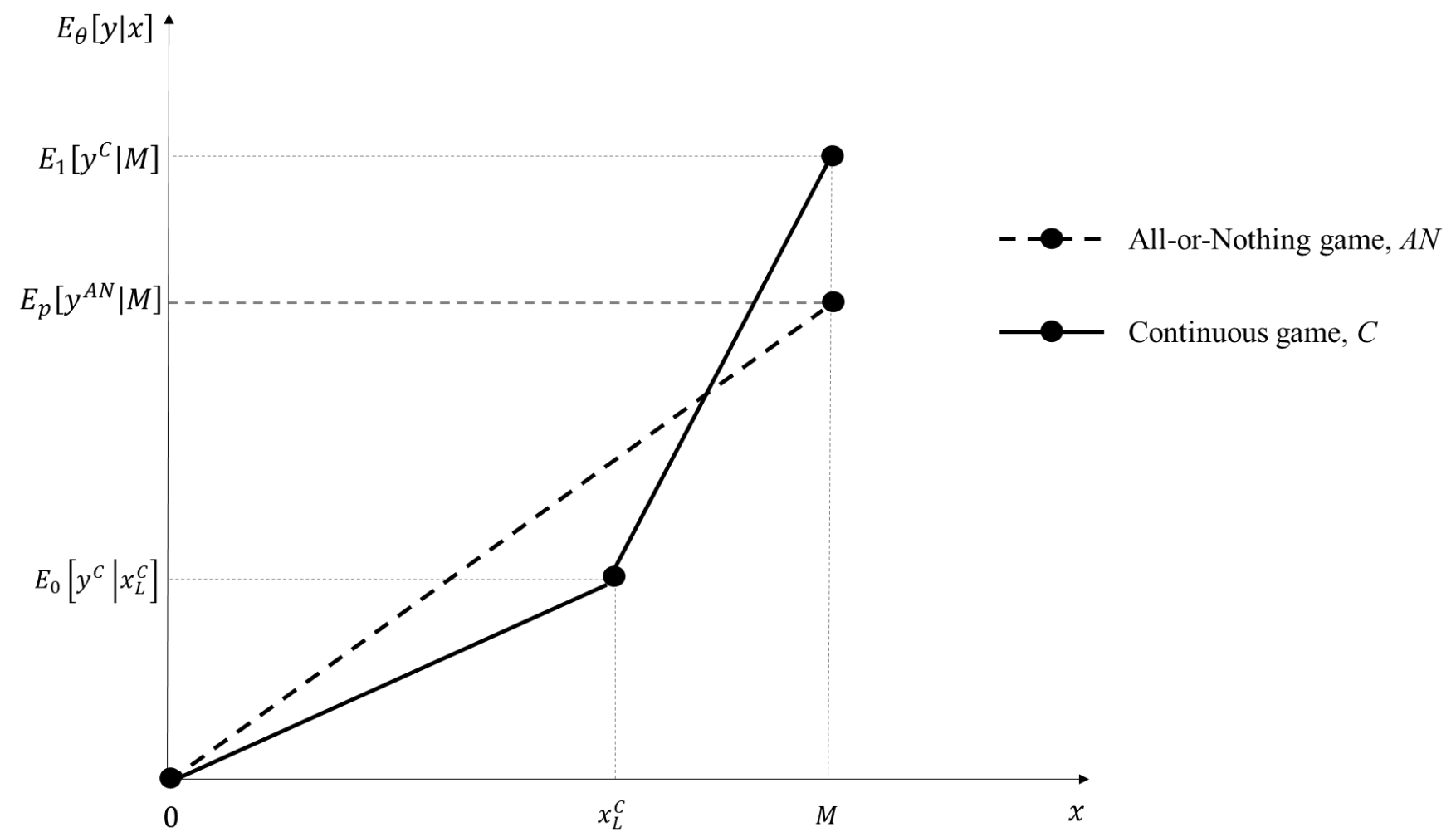

Note: The graph shows the expected increase in return when increasing investment in both versions of the trust game (All-or-Nothing, Continuous). Investments $-x$ - are on the $x$-axis and expected returns given beliefs $-E_{\theta}[y \mid x]$ - on the $y$-axis. Equilibrium belief in the All-or-Nothing treatment is equal to the prior (i.e., $\theta=p$ ) because everybody invests. Equilibrium beliefs in the Continuous treatment are given by $\theta=1$ when observing "all-in" investments $(x=M)$ and $\theta=$ 0 otherwise $\left(x=x_{L}^{C}<M\right)$. 
Figure 4: Bubble Plots of Investment and Return by Experimental treatment

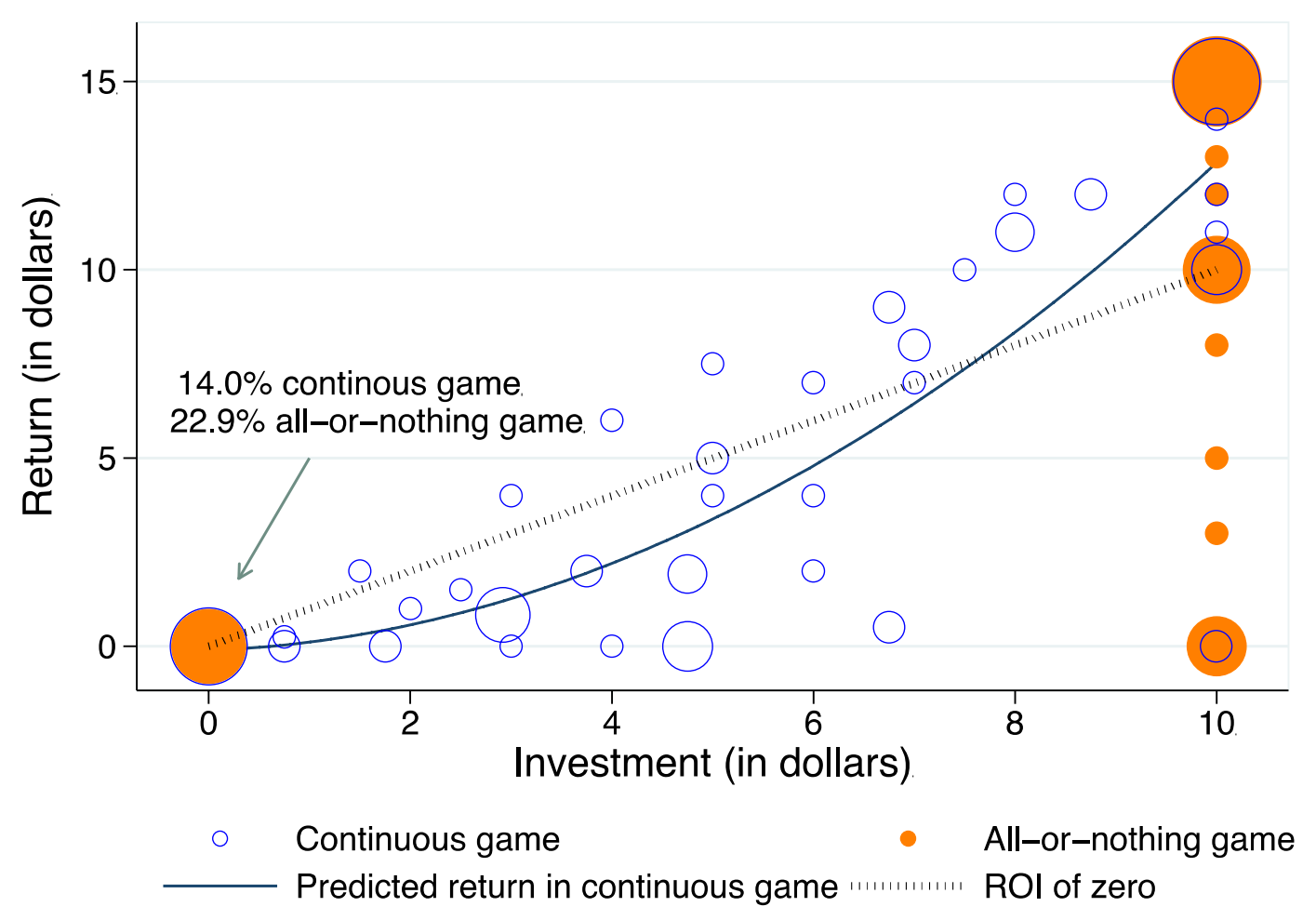

Note: Observations are plotted with bubbles, where the relative size indicates the proportion of observations in the treatment. The smallest bubble plotted represents approximately 1.5 percent and the largest bubble plotted approximately 33 percent. 
Figure 5: Distribution of Returns Conditional on Investment of \$10 by Experimental treatment

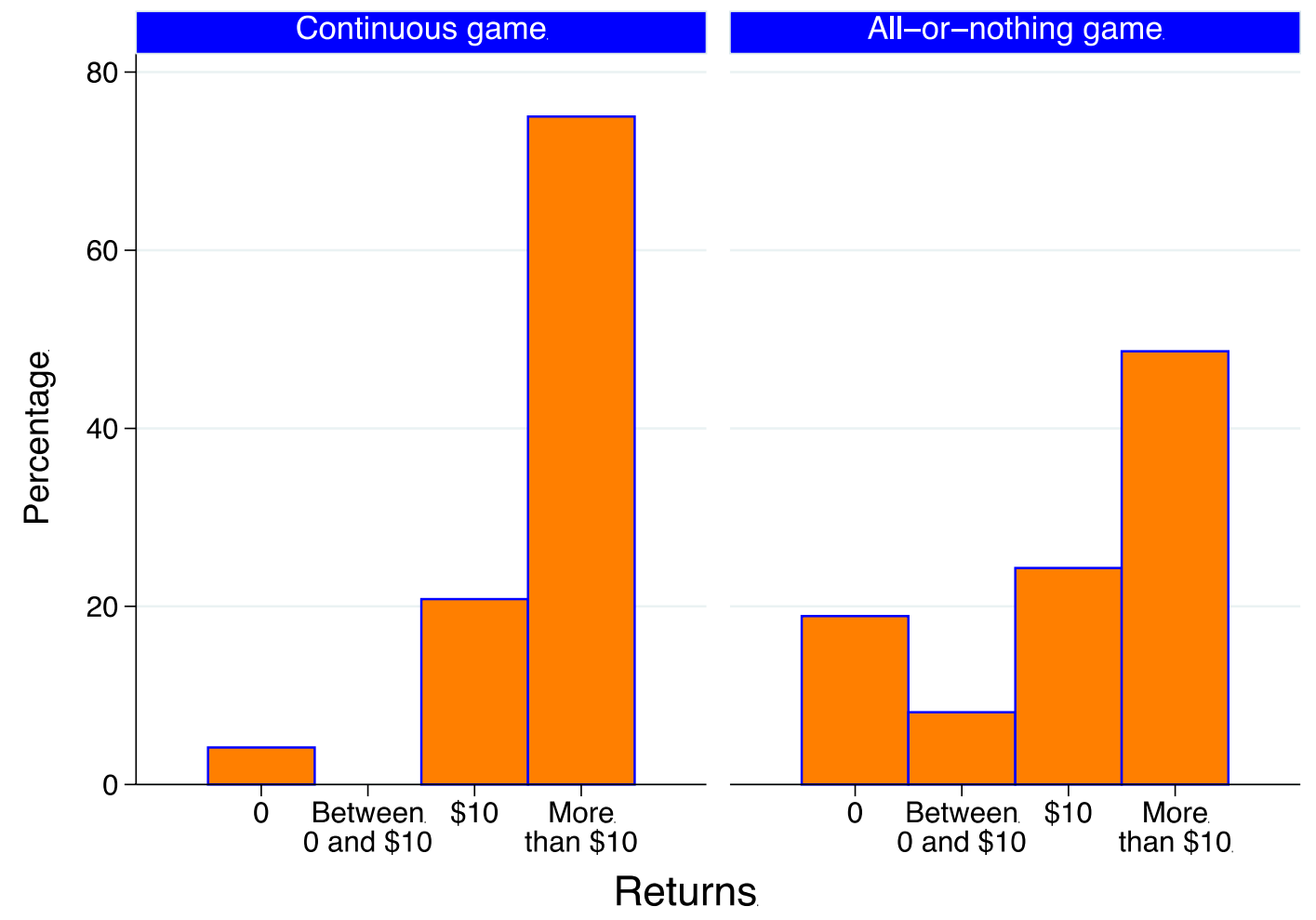


Figure 6: Investment Conditional on Attributed Trust

Panel (a): Predicted Investment Given The Degree of Trust Attributed to Investor

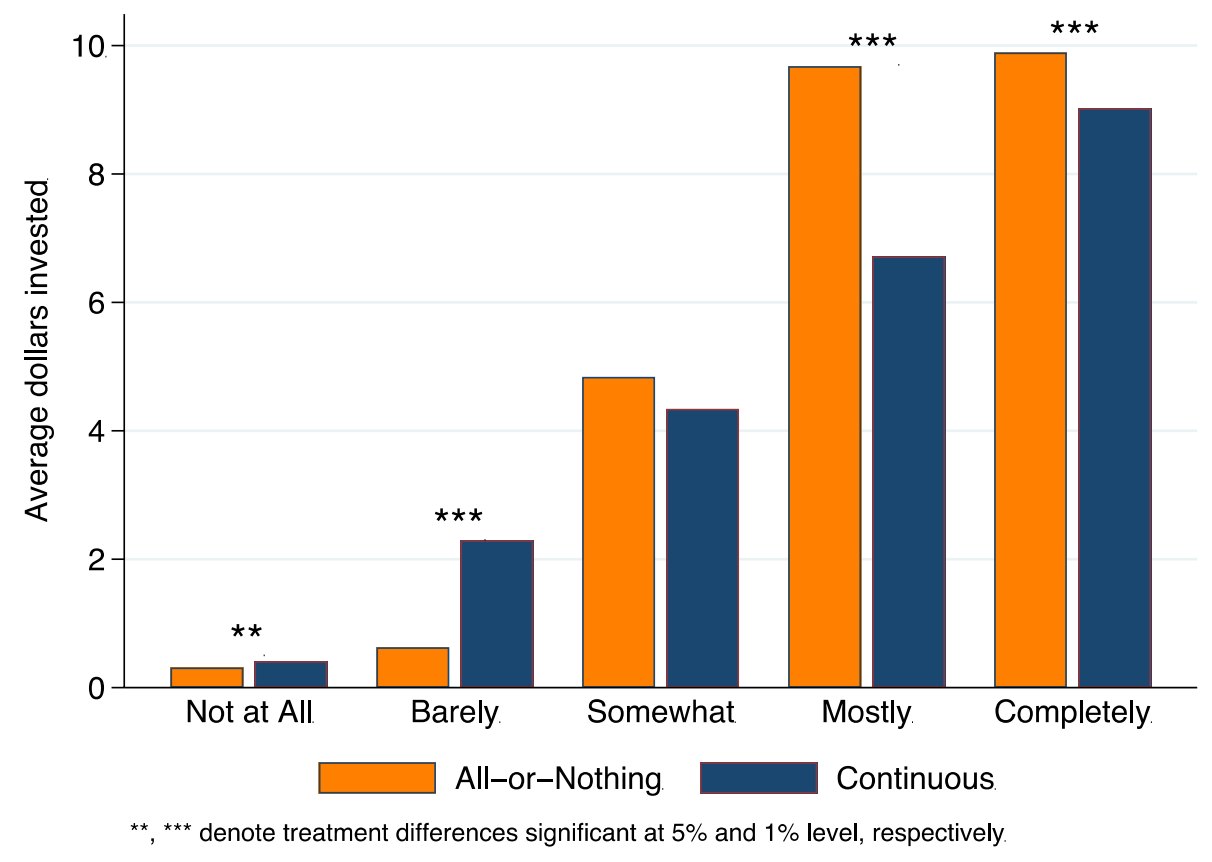

Panel (b): Proportions of Investors Predicted to Invest Their Entire \$10 Endowment Given the Degree of Trust Attributed.

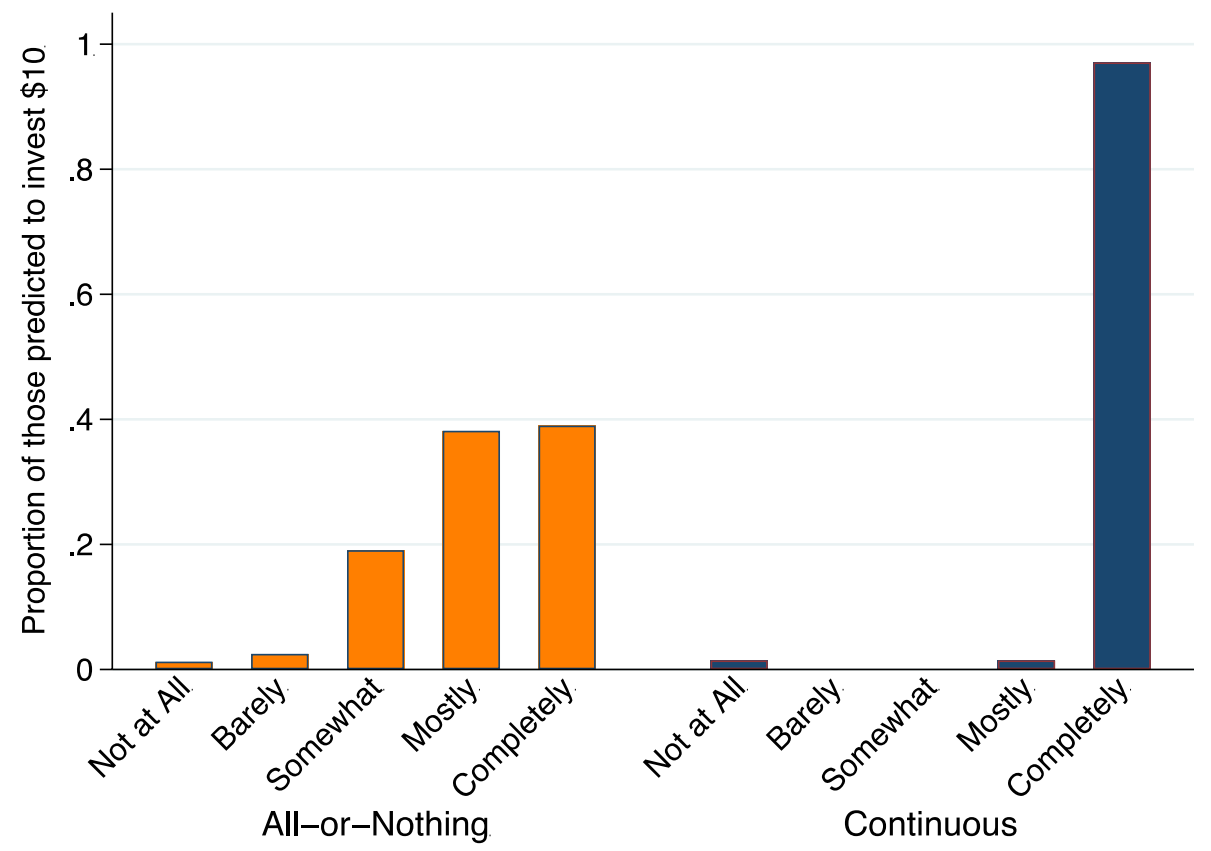

Note: The degree of trust attributed to investors was presented to participants in an ordered set from lower to higher in Experiment 2 question 2 shown in Appendix B. 
Figure 7: Predicted and Actual Investment Across Treatments

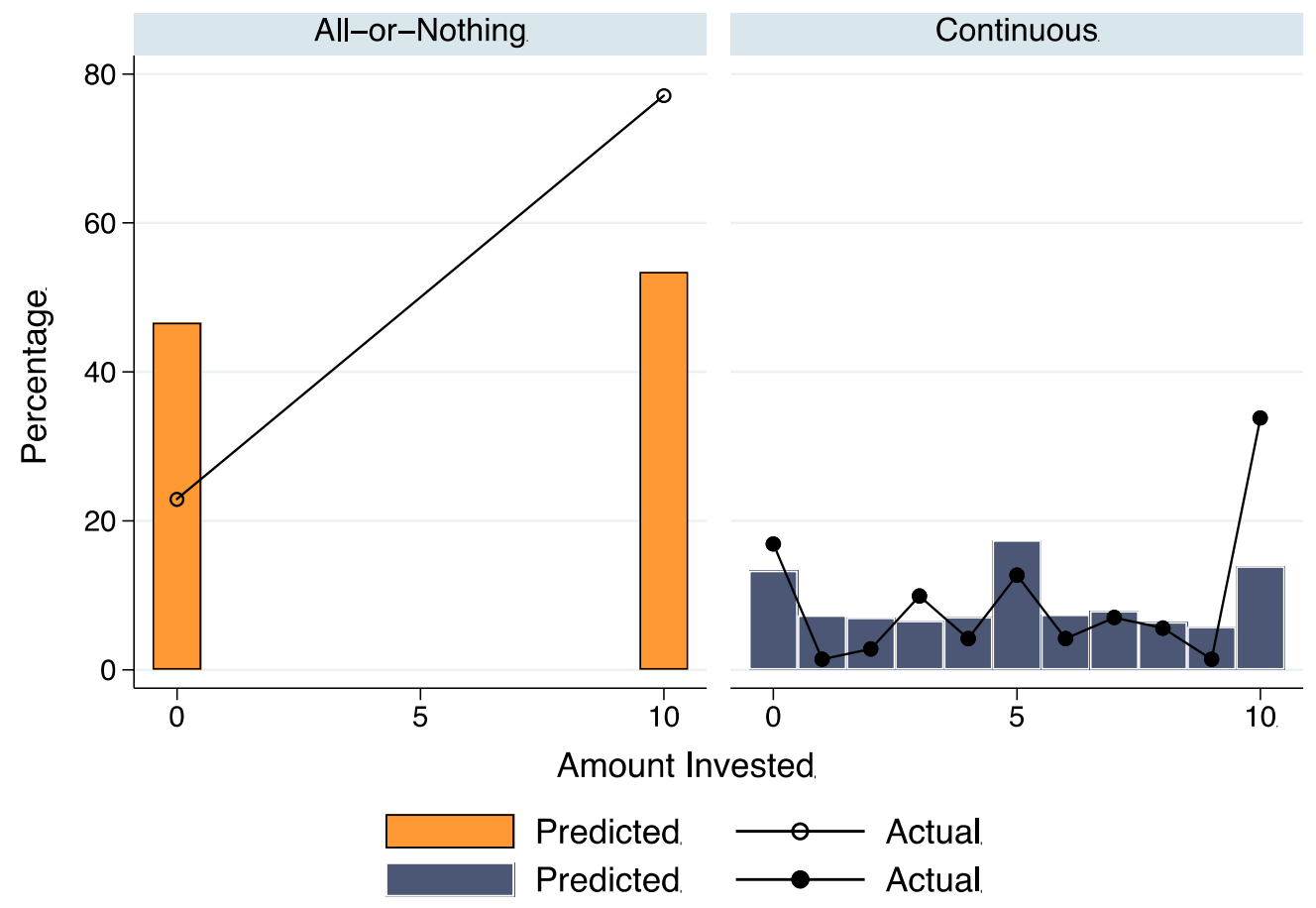

Note: Results of Experiment 2 question 3 shown in Appendix B. 
Figure 8: Predicted Reciprocity Across Treatments Given $\$ 10$ Investment

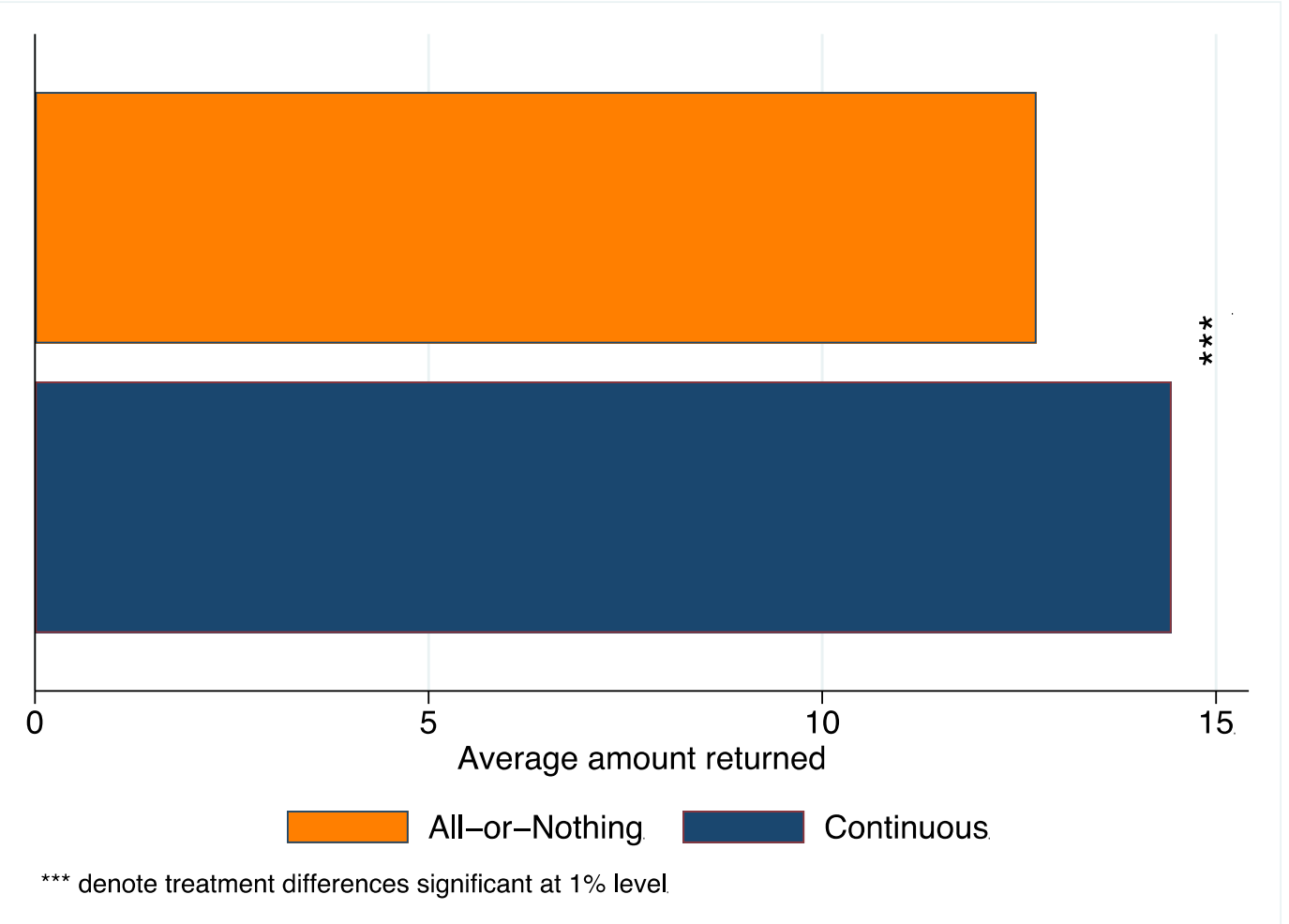

Note: Results of Experiment 2 question 4 shown in Appendix B 
Table 1: Summary Statistics for Experiment 1 by treatment

\begin{tabular}{|c|c|c|}
\hline & $\begin{array}{l}\text { Continuous game } \\
\text { (172 participants) }\end{array}$ & $\begin{array}{l}\text { All-or-Nothing game } \\
\text { (96 participants) }\end{array}$ \\
\hline \multirow{4}{*}{ Investment } & $\$ 5.60$ & $\$ 7.71$ \\
\hline & $\$ 5.00$ & $\$ 10.00$ \\
\hline & (.39) & $(.61)$ \\
\hline & 86 & 48 \\
\hline \multirow{4}{*}{$\begin{array}{l}\text { Return conditional upon investment } \\
\text { greater than zero }\end{array}$} & $\$ 6.72$ & $\$ 10.03$ \\
\hline & $\$ 6.50$ & $\$ 10.00$ \\
\hline & $(.68)$ & $(.95)$ \\
\hline & 74 & 37 \\
\hline \multirow[t]{4}{*}{ Return on Investment (ROI) } & -.15 & .00 \\
\hline & .00 & .00 \\
\hline & $(.07)$ & (.09) \\
\hline & 74 & 37 \\
\hline \multirow[t]{4}{*}{ Investor Earnings } & $\$ 10.18$ & $\$ 10.02$ \\
\hline & $\$ 10.00$ & $\$ 10.00$ \\
\hline & $(.37)$ & $(.73)$ \\
\hline & 86 & 48 \\
\hline \multirow[t]{4}{*}{ Trustee Earnings } & $\$ 11.03$ & $\$ 15.40$ \\
\hline & $\$ 12.88$ & $\$ 15.00$ \\
\hline & $(.73)$ & $(1.42)$ \\
\hline & 86 & 48 \\
\hline \multirow{4}{*}{$\begin{array}{l}\text { Investor Earnings conditional upon } \\
\text { investment greater the zero }\end{array}$} & $\$ 10.21$ & $\$ 10.03$ \\
\hline & $\$ 10.00$ & $\$ 10.00$ \\
\hline & $(.43)$ & $(.95)$ \\
\hline & 74 & 37 \\
\hline \multirow{4}{*}{$\begin{array}{l}\text { Trustee Earnings conditional upon } \\
\text { investment greater the zero }\end{array}$} & $\$ 12.81$ & $\$ 19.97$ \\
\hline & $\$ 13.00$ & $\$ 20.00$ \\
\hline & $(.63)$ & $(.95)$ \\
\hline & 74 & 37 \\
\hline \multirow{4}{*}{$\begin{array}{l}\text { Return on Investment (ROI) } \\
\text { conditional upon investment of } \$ 10\end{array}$} & .30 & .00 \\
\hline & .50 & .00 \\
\hline & $(.07)$ & (.09) \\
\hline & 24 & 37 \\
\hline
\end{tabular}

Mean, median, standard error of the mean in parenthesis, and number of observations in italics reported. ROI is defined as return less investment divided by investment and is not defined when investment is zero. 


\section{Appendix A: Instructions for the Continuous [All-or-Nothing] treatment of Experiment 1}

This is an experiment in the economics of decision-making. Various research agencies have provided funds for this research. The currency used in the experiment is experimental dollars, and they will be converted to U.S. Dollars at a rate of 1 experimental dollar to 1 dollar. At the end of the experiment your earnings will be paid to you in private and in cash. It is very important that you remain silent and do not look at other people's work. If you have any questions, or need assistance of any kind, please raise your hand and an experimenter will come to you. If you talk, laugh, exclaim out loud, etc... you will be asked to leave and you will not be paid. We expect, and appreciate, you adhering to these policies.

The participants in today's experiment will be randomly assigned into two-person groups. In addition to the group assignment each participant will also be randomly assigned to a specific type in the group, designated as Person 1 or Person 2. You and the other participant in your group will make choices that will determine your payoffs. The experiment consists of two decision stages.

In stage 1, Person 1 receives $\$ 10$ and then decides how many dollars to send to Person 2. Person 1 can send none, more than none, or all of the $\$ 10$ to Person 2. [For the All-or-Nothing game, this sentence read "Person 1 receives $\$ 10$ and then decides whether to send either $\$ 0$ or $\$ 10$ to Person"]. The amount sent by Person 1 is tripled before reaching Person 2. In stage 2, Person 2 decides how many of the dollars they received to send back to Person 1. Person 2 can send back none, more than none, or all of the amount received back to Person 1. At that point the experiment is over. Next we describe in details the decisions made by both persons in each stage of the experiment.

Stage 1: Person 1 receives $\$ 10$ and then decides how many dollars to send to Person 2. Person 1 can send none, more than none, or all of the $\$ 10$. [For the All-or-Nothing game, these sentences read "Person 1 receives $\$ 10$ and then decides whether to send either $\$ 0$ or $\$ 10$ to Person 2"]. Person 1 enters the amount sent to Person 2 in the box labeled "The amount sent by Person 1" below [Figure A5 was shown after this paragraph]. Person 1 keeps any amount that is not sent to Person 2. The amount sent by Person 1 is tripled before reaching Person 2.

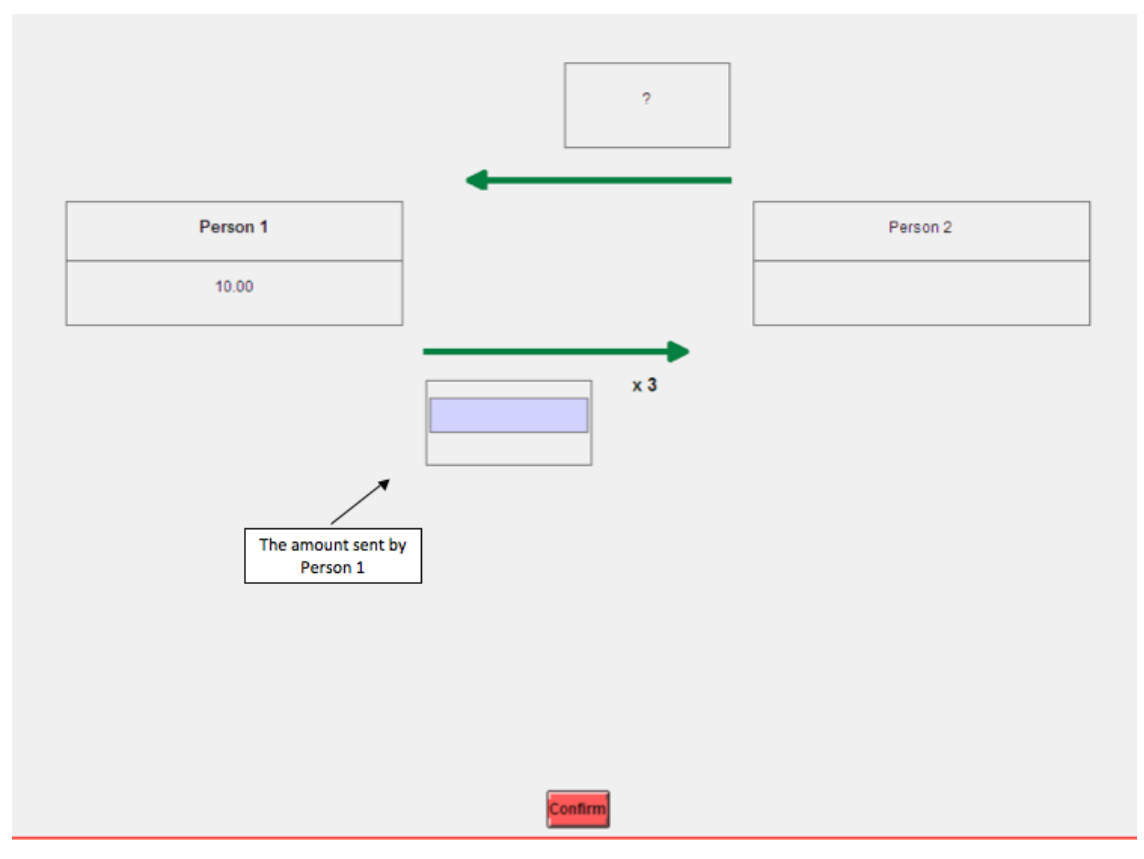


Stage 2: After learning the amount sent by Person 1, Person 2 decides how many dollars to send back to Person 1. Person 2 can send back none, more than none, or all of the amount in Person 2's account at that time. Person 2 enters the amount sent back to Person 1 in the box labeled "The amount sent back by Person 2" below [Figure A6 was shown after this paragraph]. The amount sent back by Person 2 is NOT multiplied. Person 2 keeps any amount that is not sent back to Person 1.

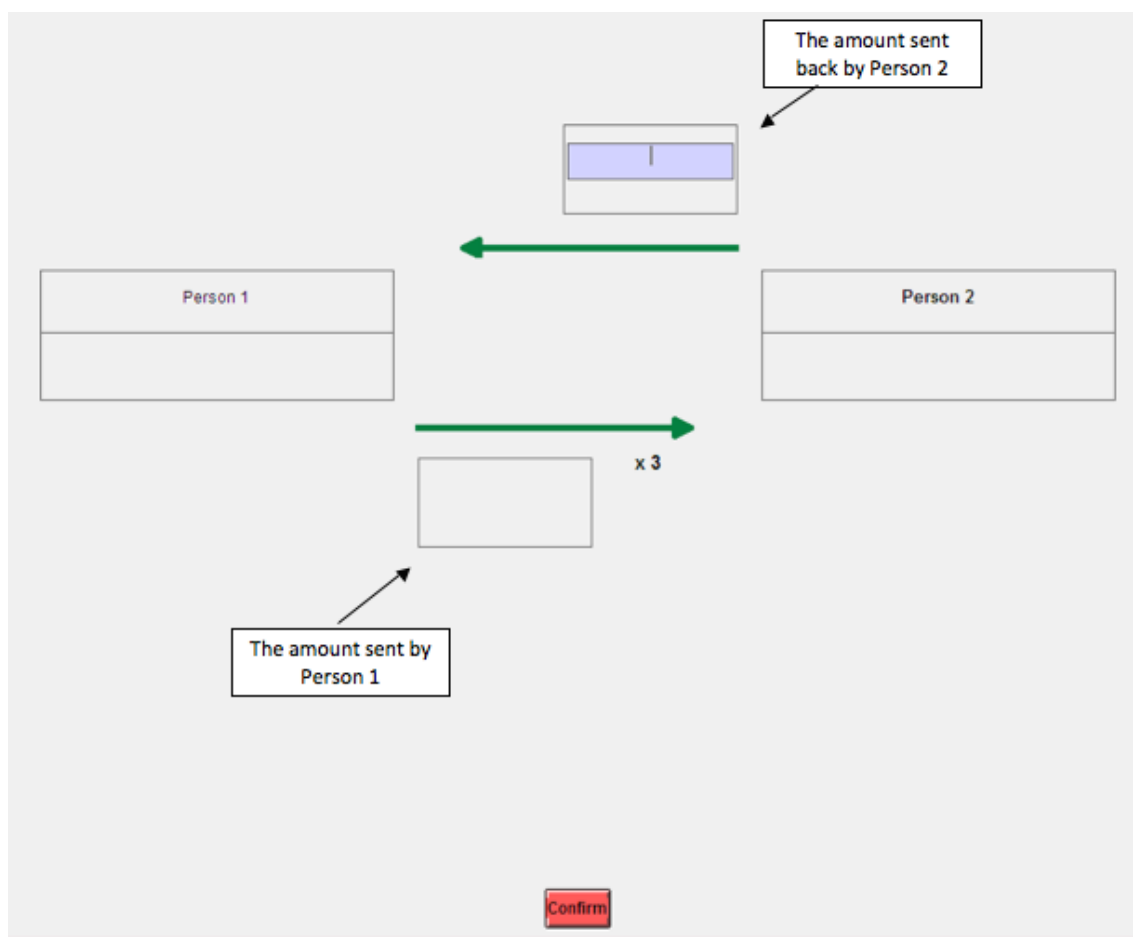

Finally, at the end of the Stage 2 the total earnings are reported to each person. Person 1's earnings will equal $\$ 10$ less the amount sent to Person 2 plus the amount sent back by Person 2. Person 2 's earning will equal three times the amount sent by Person 1 less the amount sent back to Person 1.

\section{SUMMARY}

The computer will assign you and one other participant to a two-person group, consisting of Person 1 and Person 2. In stage 1, Person 1 receives $\$ 10$ and then decides how many dollars to send to Person 2. [For the All-or-Nothing game, this sentence read "Person 1 receives $\$ 10$ and then decides whether to send either $\$ 0$ or $\$ 10$ to Person 2"]. Person 1 can send none, more than none, or all of the $\$ 10$. The amount sent by Person 1 is tripled. In stage 2, Person 2 decides how many dollars to send back to Person 1. Person 2 can send back none, more than none, or all of the amount in Person 2's account at that time. At the end of Stage 2 the total earnings are reported to each person. This experiment is now over and your earnings will be part of the total you will be paid. 


\section{QUIZ}

Before starting, we want you to answer some questions regarding the experiment to be sure you understand what will follow. After five minutes an experimenter will return to privately review your answers. Afterwards you will participate in the experiment only one time.

1. True or false: the amount sent by Person 1 is tripled before reaching Person 2's account.

2. True or false: the amount sent back by Person 2 is tripled before reaching Person 1's account.

3. What is the largest amount Person 1 can send to Person 2?

4. What is the smallest amount Person 1 can send to Person 2?

5. If Person 1 sent $\$ 4.20$ to Person 2, what is largest amount Person 2 can send back to Person 1 ?

6. If Person 1 sent $\$ 9.00$ to Person 2, what is smallest amount Person 2 can send back to Person 1 ?

7. True or false: If Person 1 sends something to Person 2, then Person 2 has to send something back to Person 1.

8. True or false: you will participate in this experiment only one time.

For the All-or-Nothing treatment, questions 3 through 7 were:

3. What are the only two possible amounts Person 1 can send to Person 2?

4. If Person 1 sent $\$ 0$ to Person 2, what is the smallest amount Person 2 can send back to Person 1 ?

5. If Person 1 sent $\$ 10$ to Person 2, what is the smallest amount Person 2 can send back to Person 1 ?

6. If Person 1 sent $\$ 10$ to Person 2, what is the largest amount Person 2 can send back to Person 1 ?

7. True or false: If Person 1 sends $\$ 10$ to Person 2, then Person 2 has to send something back to Person 1. 


\section{Appendix B: Instructions for the Continuous [All-or-Nothing] treatment of Experiment 1}

This is an experiment in the economics of decision-making. Various research agencies have provided funds for this research. The currency used in the experiment is experimental dollars, and they will be converted to U.S. Dollars at a rate of 1 experimental dollar to 1 dollar. At the end of the experiment your earnings will be paid to you in private and in cash. It is very important that you remain silent and do not look at other people's work. If you have any questions, or need assistance of any kind, please raise your hand and an experimenter will come to you. If you talk, laugh, exclaim out loud, etc... you will be asked to leave and you will not be paid. We expect, and appreciate, you adhering to these policies.

The participants in today's experiment will be randomly assigned into two-person groups. In addition to the group assignment each participant will also be randomly assigned to a specific type in the group, designated as Person 1 or Person 2. You and the other participant in your group will make choices that will determine your payoffs. The experiment consists of two decision stages.

In stage 1, Person 1 receives $\$ 10$ and then decides how many dollars to send to Person 2. Person 1 can send none, more than none, or all of the $\$ 10$ to Person 2. [For the All-or-Nothing game, this sentence read "Person 1 receives $\$ 10$ and then decides whether to send either $\$ 0$ or $\$ 10$ to Person"]. The amount sent by Person 1 is tripled before reaching Person 2. In stage 2, Person 2 decides how many of the dollars they received to send back to Person 1. Person 2 can send back none, more than none, or all of the amount received back to Person 1. At that point the experiment is over. Next we describe in details the decisions made by both persons in each stage of the experiment.

Stage 1: Person 1 receives $\$ 10$ and then decides how many dollars to send to Person 2. Person 1 can send none, more than none, or all of the $\$ 10$. [For the All-or-Nothing game, these sentences read "Person 1 receives $\$ 10$ and then decides whether to send either $\$ 0$ or $\$ 10$ to Person 2 "]. Person 1 enters the amount sent to Person 2 in the box labeled "The amount sent by Person 1" below [Figure A5 was shown after this paragraph]. Person 1 keeps any amount that is not sent to Person 2. The amount sent by Person 1 is tripled before reaching Person 2.

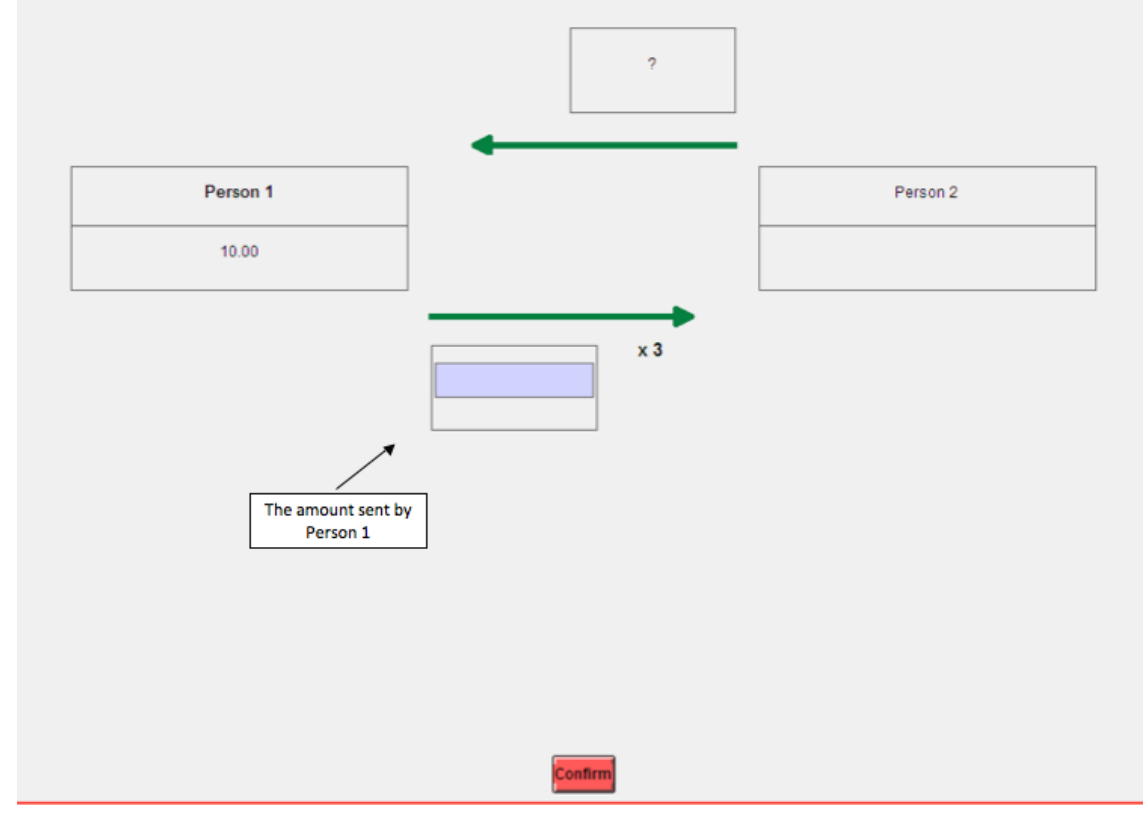


Stage 2: After learning the amount sent by Person 1, Person 2 decides how many dollars to send back to Person 1. Person 2 can send back none, more than none, or all of the amount in Person 2's account at that time. Person 2 enters the amount sent back to Person 1 in the box labeled "The amount sent back by Person 2" below [Figure A6 was shown after this paragraph]. The amount sent back by Person 2 is NOT multiplied. Person 2 keeps any amount that is not sent back to Person 1.

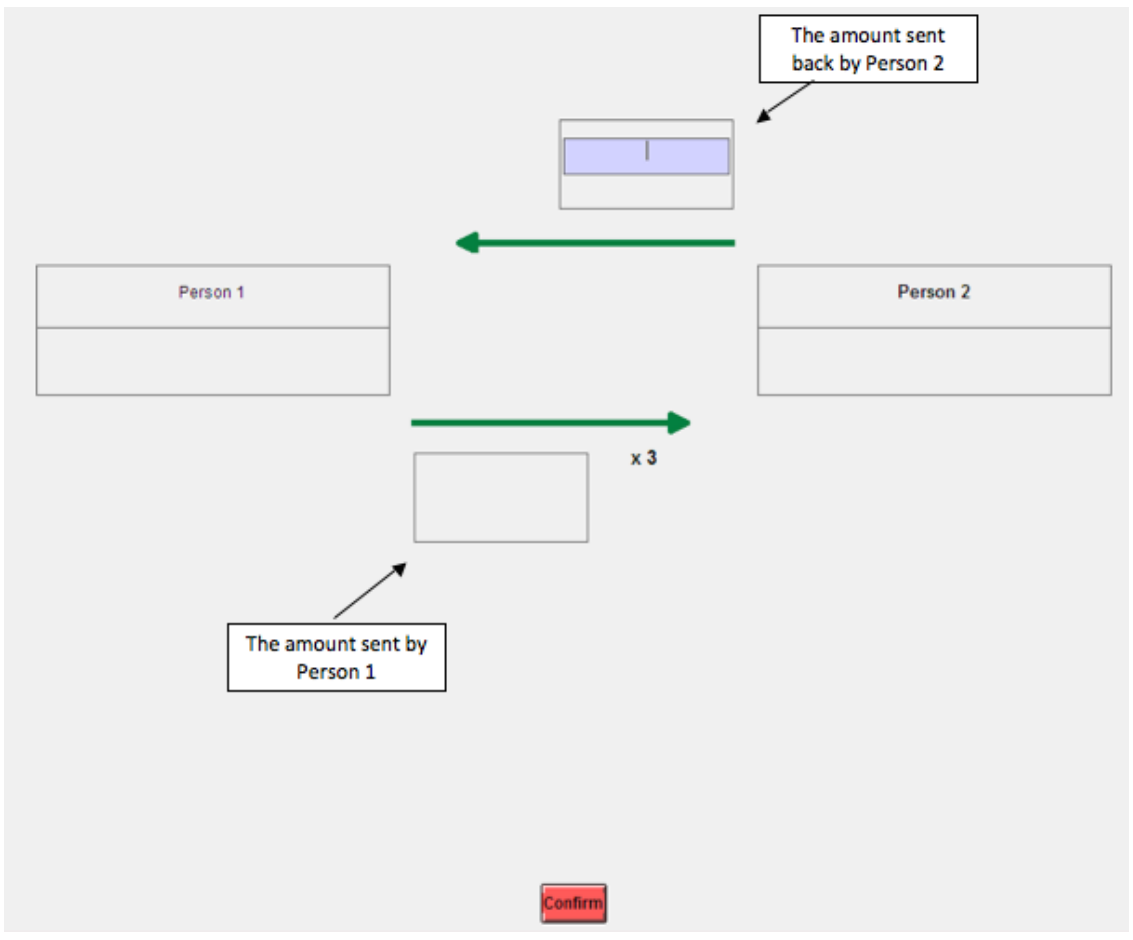

Finally, at the end of the Stage 2 the total earnings are reported to each person. Person 1's earnings will equal $\$ 10$ less the amount sent to Person 2 plus the amount sent back by Person 2. Person 2 's earning will equal three times the amount sent by Person 1 less the amount sent back to Person 1 .

\section{SUMMARY}

The computer will assign you and one other participant to a two-person group, consisting of Person 1 and Person 2. In stage 1, Person 1 receives $\$ 10$ and then decides how many dollars to send to Person 2. [For the All-or-Nothing game, this sentence read "Person 1 receives $\$ 10$ and then decides whether to send either $\$ 0$ or $\$ 10$ to Person 2"]. Person 1 can send none, more than none, or all of the $\$ 10$. The amount sent by Person 1 is tripled. In stage 2, Person 2 decides how many dollars to send back to Person 1. Person 2 can send back none, more than none, or all of the amount in Person 2's account at that time. At the end of Stage 2 the total earnings are reported to each person. This experiment is now over and your earnings will be part of the total you will be paid. 


\section{QUIZ}

Before starting, we want you to answer some questions regarding the experiment to be sure you understand what will follow. After five minutes an experimenter will return to privately review your answers. Afterwards you will participate in the experiment only one time.

9. True or false: the amount sent by Person 1 is tripled before reaching Person 2's account.

10. True or false: the amount sent back by Person 2 is tripled before reaching Person 1's account.

11. What is the largest amount Person 1 can send to Person 2?

12. What is the smallest amount Person 1 can send to Person 2?

13. If Person 1 sent $\$ 4.20$ to Person 2, what is largest amount Person 2 can send back to Person 1 ?

14. If Person 1 sent $\$ 9.00$ to Person 2, what is smallest amount Person 2 can send back to Person 1 ?

15. True or false: If Person 1 sends something to Person 2, then Person 2 has to send something back to Person 1.

16. True or false: you will participate in this experiment only one time.

For the All-or-Nothing treatment, questions 3 through 7 were:

8. What are the only two possible amounts Person 1 can send to Person 2?

9. If Person 1 sent $\$ 0$ to Person 2, what is the smallest amount Person 2 can send back to Person 1?

10. If Person 1 sent $\$ 10$ to Person 2, what is the smallest amount Person 2 can send back to Person 1 ?

11. If Person 1 sent $\$ 10$ to Person 2, what is the largest amount Person 2 can send back to Person 1 ?

12. True or false: If Person 1 sends $\$ 10$ to Person 2, then Person 2 has to send something back to Person 1 . 


\section{Appendix B: Instructions and Questions for Continuous [All-or-Nothing] Versions of Experiment 2}

This is a computerized experiment in the economics of decision-making. Various research agencies have provided funds for this research. By following the instructions carefully and making good decisions, you may earn an additional amount of money besides the show up bonus of $\$ 7$. The actual amount of additional money that you may earn will depend on your decisions and the decisions of others. Your money will be paid to you in cash after the experiment ends.

There are a couple basic rules you must follow:

1. Do not talk to others or make private vocalizations at any time during the experiments.

2. Do not discuss these experiments with others outside of the laboratory.

3. If you have any questions after the instructions are over, or during the experiments, please raise your hand. An experimenter will come to your location and answer your questions privately.

\section{General Description of the Experiments}

The experiment consists of a computerized questionnaire broken into 3 separate sections with varying decision tasks. In each of the separate sections, one randomly chosen decision determines your earnings from the section. Your overall income from the experiment will be based on the sum of earnings from the 3 separate sections of the questionnaire. It is in your best interest to make a careful decision in all possible situations. Neither during nor after the experiment will you or any other participant in this experiment be informed about the true identity of those with whom you are interacting or who interacted in previous experiments.

Researchers at the Economic Science Institute (ESI) have conducted an experiment using an anonymous two-person economic interaction (between a Person 1 and a Person 2) over a computer network. A description of that experiment follows. 


\section{EXPLANATION OF THE ORIGINAL EXPERIMENT}

\section{IMPORTANT: You will not participate in the experiment explained below, but it is important that you understand it because you will make guesses related to people and decisions from this original experiment.}

Below are the instructions that were provided to participants in the original experiment.

This is an experiment in the economics of decision-making. Various research agencies have provided funds for this research. The currency used in the experiment is experimental dollars, and they will be converted to U.S. Dollars at a rate of 1 experimental dollar to 1 dollar. At the end of the experiment your earnings will be paid to you in private and in cash. It is very important that you remain silent and do not look at other people's work. If you have any questions, or need assistance of any kind, please raise your hand and an experimenter will come to you. If you talk, laugh, exclaim out loud, etc... you will be asked to leave and you will not be paid. We expect, and appreciate, you adhering to these policies.

The participants in today's experiment will be randomly assigned into two person groups. In addition to the group assignment each participant will also be randomly assigned to a specific type in the group, designated as Person 1 or Person 2. You and the other participant in your group will make choices that will determine your payoffs. The experiment consists of two decision stages.

In stage 1, Person 1 receives $\$ 10$ and then decides how many dollars to send to Person 2. Person 1 can send none, more than none, or all of the $\$ 10$ to Person 2. [For the All-or-Nothing version, this sentence read "Person 1 receives $\$ 10$ and then decides whether to send either $\$ 0$ or $\$ 10$ to Person']. The amount sent by Person 1 is tripled before reaching Person 2. Person 1 keeps any amount that is not sent to Person 2. In stage 2, Person 2 decides how many of the dollars they received to send back to Person 1. Person 2 can send back none, more than none, or all of the amount received back to Person 1 . The amount sent back by Person 2 is NOT multiplied. Person 2 keeps any amount that is not sent back to Person 1 . At that point the experiment is over.

SITUATION UNDERLYING TODAY'S EXPERIMENT: After collecting extensive data from the experiment described above, researchers are now interested to learn more about how you match attributions to transfer amounts in the economic interaction described above.

You can always return to the description of the original experiment by clicking upon the tab above. 


\section{Incentivized Belief Elicitation Task Questions (Experiment 2)}

Text in italics listed below the question explain version differences.

\section{Part 1 Questions}

Consider each of the examples below, then indicate what you believe the Person 1s described most likely transferred in the experiment. The trust attributions we are considering are from an ordered set not trusting, barely trusting, somewhat trusting, mostly trusting, completely trusting describing a Person 1's overall degree of trust in the economic interaction. Your anonymized responses will be used along with responses from other participants here today for scoring your answers to questions we ask in the next part.

Please hit ENTER or click the Set Value button after providing each answer below.

Person 1 started with $\$ 10$ and had the choice to transfer < description> of the $\$ 10$ to Person 2. Given their available options how much do you think a Person 1 who was <attribute> would have transferred to Person 2?

In both task versions questions $1-5$ used the attribute

1. not trusting

2. barely trusting

3. somewhat trusting

4. mostly trusting

5. completely trusting

All-or-Nothing version

- The description was "all or none"

- Values listed were 0 or 10

\section{Continuous version}

- The description was "any amount"

- Values listed were 0, 1, 2, ..., 9, 10 


\section{Part 2 Questions}

Others participating in today's experiment will also indicate their beliefs about amounts most likely transferred by the Person 1s described in the examples below. You can earn money by correctly guessing what others in today's experiment indicate they believe.

You can earn up to $\$ 10$ for your selected guess if it is the same as the most common guess for that question in today's experiment. We will calculate payment for these guesses (depending on accuracy) using the following scoring rule: If your guess is exactly the same as any most common guess (or most common guesses in the case of ties) observed in the distribution of all other participants' guesses you will earn $\$ 10$. If your guess is not the same as the most common guess(s) observed in the distribution of all other participants' guesses you will earn $\$ 0$.

Please hit ENTER or click the Set Value button after providing each answer below.

A <attribute> Person 1 would have transferred to Person 2? Others' most common answer:

In both versions questions $1-5$ used the attribute

1. not trusting

2. barely trusting

3. somewhat trusting

4. mostly trusting

5. completely trusting

All-or-Nothing version

- The description was "all or none"

- Values listed were 0 or 10

\section{Continuous version}

- The description was "any amount"

- Values listed were 0, 1, 2, ..., 9, 10 


\section{Part 3 Questions}

Person 1 started with $\$ 10$ and had the choice to transfer any amount of the $\$ 10$ to Person 2. Please indicate the distribution that you think matches the distribution of Person 1 transfer decisions that occurred in the original experiment. You can earn up to $\$ 10$ for your guess. The closer your guess is to the correct average (from the original experiment), the more you can earn. We will calculate payment for the selected guess (depending on accuracy) using the following scoring rule: If your guess is exactly right or within $2.5 \%$ above or below the correct average you will earn $\$ 10$. If your guess is further off than $2.5 \%$ you will earn $\$ 0.25$ divided by the (absolute) distance between your guess and the correct average.

Your guesses for the "N" questions below must total to $100 \%$.

Person 1 started with $\$ 10$ and had the choice to transfer <description> of the $\$ 10$ to Person 2 . What percent of Person 1's transferred:

Please hit ENTER or click the Set Value button after providing each answer below.

In both versions participants entered a value between $0 \%$ and $100 \%$ and the sum of the questions were required to sum up to $100 \%$.

All-or-Nothing version

- The description was "all or none"

- Two questions asked:

1. $\$ 0$ of their $\$ 10$ to Person 2

2. $\$ 10$ of their $\$ 10$ to Person 2

Continuous version

- The description was "any amount"

- Eleven questions asked:

1. $\$ 0$ of their $\$ 10$ to Person 2

2. $\$ 1$ of their $\$ 10$ to Person 2

3. $\$ 2$ of their $\$ 10$ to Person 2

4. $\$ 3$ of their $\$ 10$ to Person 2

5. $\$ 4$ of their $\$ 10$ to Person 2

6. $\$ 5$ of their $\$ 10$ to Person 2

7. $\$ 6$ of their $\$ 10$ to Person 2

8. $\$ 7$ of their $\$ 10$ to Person 2

9. $\$ 8$ of their $\$ 10$ to Person 2

10. $\$ 9$ of their $\$ 10$ to Person 2

11. $\$ 10$ of their $\$ 10$ to Person 2 


\section{Part 4 Questions}

Taking the perspective of a Person 2 from the original experiment, consider each of the examples below, then guess the average amount a Person 2 returned to Person 1 for each example. Your guess about Person 2's return can include amounts with dollars and cents.

You can earn up to $\$ 10$ for your guess, depending on accuracy. We will score guesses for accuracy using the following rule: If your guess is exactly right or not more than $\$ 0.25$ away from the average amount returned among Person $2 \mathrm{~s}$ facing the situation described in the original experiment, you will earn $\$ 10$. If your estimate is further off than $\$ 0.25$ from the average you will earn $\$ 2.50$ divided by the (absolute) distance between your guess and the average.

Please hit ENTER or click the Set Value button after providing each answer below.

How much do you think the average Person 2 returned to Person 1 after receiving \$<amount> (the tripled transfer) from a Person 1 who had an option to transfer <description> of their $\$ 10$ endowment? Person 2 probably returned:

In both versions participants entered a value between 0 and the amount received (which varies by question).

All-or-Nothing version

- The description was "all or none"

- One question asked:

1. Amount was 30

\section{Continuous version}

- The description was "any amount"

- 10 questions asked:

1. Amount was 3

2. Amount was 6

3. Amount was 9

4. Amount was 12

5. Amount was 15

6. Amount was 18

7. Amount was 21

8. Amount was 24

9. Amount was 27

10. Amount was 30 